Research Article

\title{
Numerical Investigation of Pyrotechnical Initiators and Their Impact in Airbag Inflator Applications: Ballistic Modeling and Functional Analysis
}

\author{
Peng Li ${ }^{1,2}$, Chi-Yao Chang ${ }^{1,}{ }^{*}$, Amsini Sadiki ${ }^{2,3,4}$
}

1. Joyson Safety Systems Aschaffenburg, 63743 Germany; E-Mails: penglee9999@gmail.com; chiyao.chang@gmx.de

2. Technical University of Darmstadt, Institute for Energy and Power Plant Technology, Darmstadt, 64287 Germany; E-Mail: sadiki@ekt.tu-darmstadt.de

3. Technical University of Darmstadt, Reactive Flows and Diagnostics, Darmstadt, 64287 Germany

4. Laboratoire de Modélisation Mécanique, Energétique et Matériaux, ISTA-Kinshasa, Ndolo, DRCongo

* Correspondence: Chi-Yao Chang; E-Mail: chi-yao.chang@gmx.de

Academic Editor: Francesco Gabriele Galizia

Special Issue: Energy Efficiency in Flexible and Reconfigurable Manufacturing: Emerging Trends, Models and Applications in the Industry 4.0 Era

Journal of Energy and Power Technology

2021, volume 3 , issue 2

doi:10.21926/jept.2102026
Received: April 02, 2021

Accepted: May 31, 2021

Published: June 28,2021

\begin{abstract}
A numerical model describing the ballistic behavior of a commercially used initiator is presented in this article. This model was built on the principle of conservation of mass and energy in the multi-phase framework incorporated with multi-loaded conditions. After obtaining the information about the grain size distribution in each composite, a fixing factor was proposed based on the surface area ratio of the composites. Thus, the solid propellant burning process based on distributed grain size was described, and the burn rate parameters of the applied pyrotechnic compositions were re-evaluated for different preconditioned temperature levels according to Vieille's law. The influence of bridge wire and initiator metal cap was further modeled concerning their characteristic properties according to the observed measurements. The validation of the entire initiator model in the closed bomb test showed
\end{abstract}

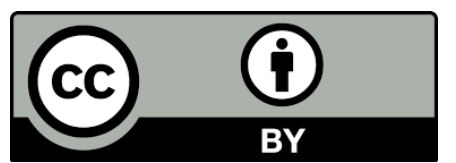

(C) 2021 by the author. This is an open access article distributed under the conditions of the Creative Commons by Attribution License, which permits unrestricted use, distribution, and reproduction in any medium or format, provided the original work is correctly cited. 
quantitative agreement with the measured pressure evolution, while the parameter study for evaluating the ballistic sensitivity of each component delivered some insights into the product development process. Furthermore, the configuration of a cold gas inflator was utilized to evaluate the initiator impact for a realistic application, where the shock wave intensity during deployment serves the main function in the inflator design. Incorporated with CFD simulations to capture the shock wave propagation, OD-3D coupling strategy for initiator ballistics to inflator configuration was realized. Besides, the simulation results reflected the physical conditions in a proper manner. In particular, the parameter study led to a better understanding of interactions between inflator components, which were barely possible to be quantified through the measurements. The proposed initiator model could also be used in combination with other mechanical principles as a component of pyrotechnic devices such as pin-puller, electric line cutters, or airbag inflators. The detailed information gained in describing the physical properties enabled us to assess the existing design quantitatively and to have better control of the product quality.

\section{Keywords}

Ballistic modeling; airbag inflator; CFD; shockwave propagation

\section{Nomenclature}

\section{Abbreviations}

$\begin{array}{ll}\text { BPN } & \text { boron potassium nitrate } \\ \text { BWBO } & \text { bridge wire burn out time } \\ \text { CDF } & \text { cumulative distribution function } \\ \text { CFD } & \text { computational fluid dynamics } \\ \text { NSI } & \text { NASA standard initiator } \\ \text { PDF } & \text { probability density function } \\ \text { PEP } & \text { propellant evaluation program } \\ \text { THPP } & \text { titanium hydride potassium perchlorate } \\ \text { ZPP } & \text { zirconium potassium perchlorate }\end{array}$

\section{Symbols}

$\alpha$

$\dot{m}$

$\dot{Q}$

$\eta, \beta$

$\eta_{1}$ merging ratio of PDFs

mass flow rate $(\mathrm{kg} / \mathrm{s})$

heat transfer between reaction products and system surroundings $(\mathrm{J} / \mathrm{s})$

model constants of Weibull distribution

mass fraction of condensed (liquid) phase

heat capacity ratio

density $\left(\mathrm{kg} / \mathrm{m}^{3}\right)$

initiator metal cap stress (MPa)

resistance $(\Omega)$ 


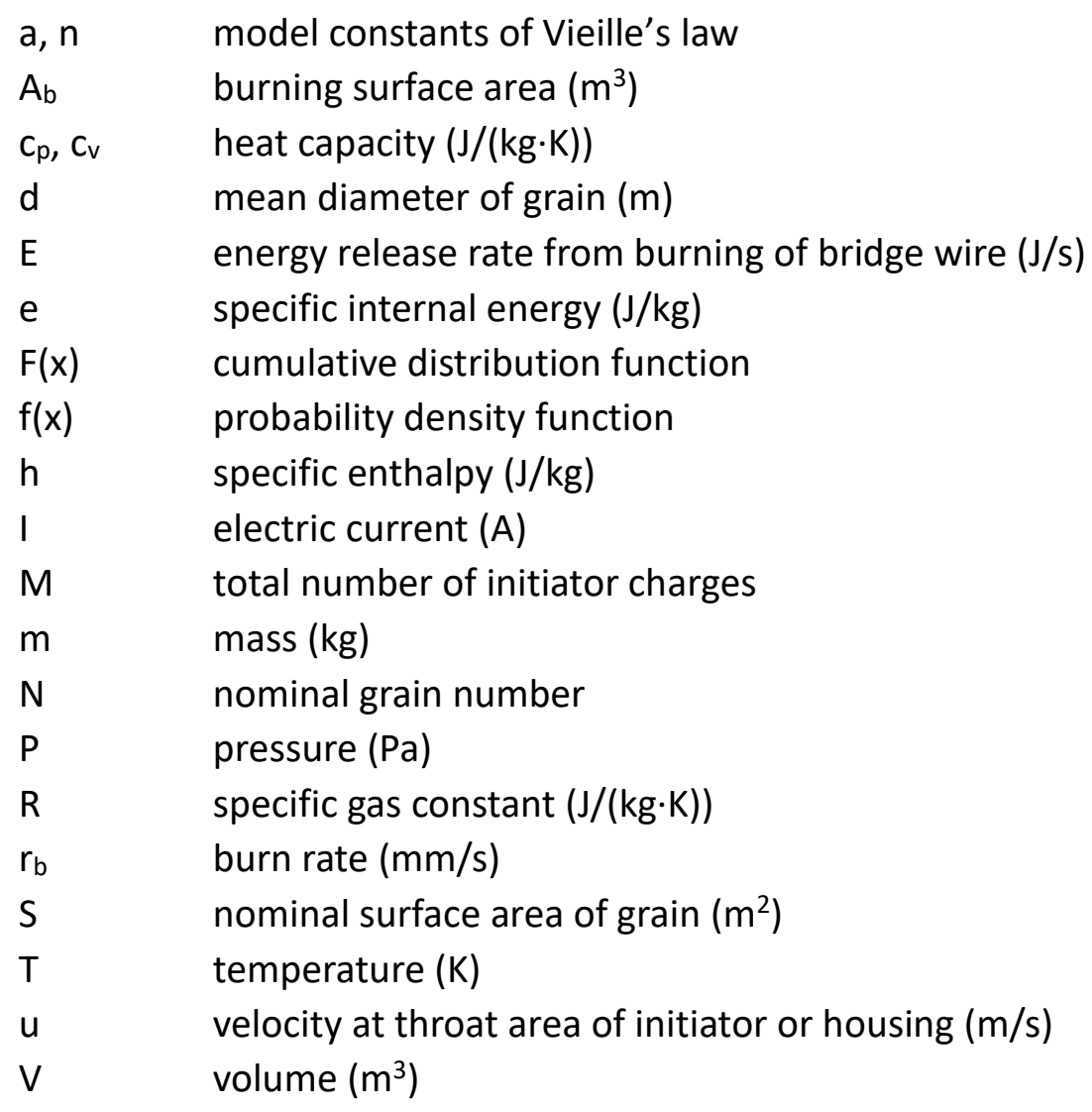

\section{Superscripts}

i individual pyrotechnic charge

\section{Subscripts}

$\begin{array}{ll}\text { "1" } & \text { 1st system (combustion chamber) } \\ \text { "2" } & \text { 2nd system (closed vessel or inflator housing) } \\ \text { b } & \text { burning } \\ \text { g } & \text { gas phase } \\ \text { H } & \text { housing } \\ \text { I } & \text { condensed (liquid) phase } \\ \text { s } & \text { solid reactant }\end{array}$

\section{Introduction}

Initiators are widely used in the military [1, 2], aerospace [3, 4], and automotive applications [58] as pin pullers [9-11], valves [12-15], and airbag inflators [16-19], respectively. Due to the fast triggering property, an initiator is primarily used to ignite more difficult-to-ignite materials, e.g., solid propellants and thermites. The commonly used pyrotechnic materials for electric initiators are ZPP (zirconium potassium perchlorate), THPP (titanium hydride potassium perchlorate), and BPN (boron potassium nitrate), which exhibit fast-burning rates, high-energy density, and easy ignition characteristics. 
When a firing current is applied to the bridge wire through the conducting pins, the bridge wire glows, releasing a large amount of heat to the pyrotechnic charges. The solid propellants (booster and main propellant) are subsequently ignited and undergo a rapid chemical reaction to produce both condensed phase and gas-phase products. The gas products eventually exert high pressure on the initiator. If the generated pressure is sufficient to overcome the resisting strain of the initiator metal cap, it breaks with mass and energy flows into the subsystem to ignite larger pyrotechnic tablets or create mechanical movements.

Closed bomb tests [20-22] are commonly used to evaluate the initiator performance and to control the production quality by measuring the pressure evolution with the help of pressure sensors. In the schematic of a closed bomb test shown in Figure 1, an initiator is actuated into a closed bomb which is a vessel with constant volume. However, due to the highly dynamic characteristics of the initiator deployment process (less than $2 \mathrm{~ms}$ ), most physical properties are extremely difficult to measure, and the visualization of the flow patterns is even more challenging. Hence, the numerical modeling approach of initiator deployment provides another possible strategy to understand the working mechanisms and impacts of each element of the initiator.

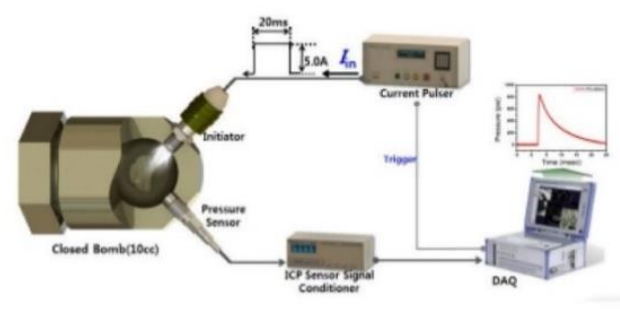

(a)

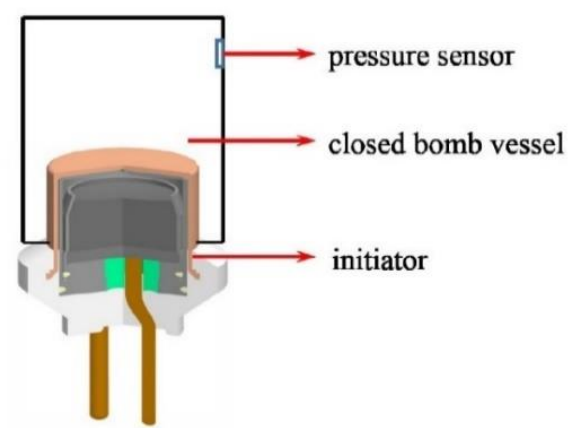

(b)

Figure 1 Schematic of closed bomb test. (a) Closed bomb test [23] and (b) actuation of the initiator in a closed bomb.

One of the earliest simulation models for an initiator-driven device was developed by Kuo et al. [24]. In their work, a 1D model was developed as a quick first-order estimation to analyze the dynamic behavior of the NASA Standard Initiator (NSI) driven pin puller. However, the chemical reaction, the pressure effects on the burn rate, condensed phase, and the shock waves were not considered. This limitation was overcome by Gonthier et al. [10, 11], who suggested a timedependent mathematical model derived from conservation principles and other constitutive relations. The model accounted for multiple pyrotechnic grains, variable burning surface areas, combustion product mass flow rates through an orifice located within the device, and pyrotechnic shocks. Gonthier predicted the pressure and temperature histories based on this model. Further, Powers [25] investigated the sensitivity of the kinetic energy imparted to the pin puller as a function of system parameters. In another study [26], Gonthier investigated the choked flow effects in the pin puller and presented the model sensitivity against the changes in the cross-sectional area of the orifice. It is important to note that the initiator's performance is usually specified by its peak pressure level in a closed bomb. However, he did not address the unsteady pressure fluctuation in the initiation process. On the other hand, Lee [27] was capable of examining the unsteady effects by utilizing a 1D unsteady dynamic gas model. He showed that unsteady flow effects present in an 
initiator could not be neglected when the device completes its stroke, well before the gas dynamics in the device reaches a steady state. Jang et al. [9] developed an analytical model based on 1D gas dynamics for an ideal gas to understand the physics and predict the functional performance of a pin puller. The validity of the model was assessed by additional firing tests with different amounts of pyrotechnic charges.

In all of the aforementioned studies, all the pyrotechnic granules in the initiator were assumed to be of the same size from the production perspective, as it would not have been commercially possible. Instead, the granules with specific distribution had to be utilized. Han et al. [20] modeled the combustion of ZPP in a closed vessel by applying the Rosin-Rammler distribution [28], considering the cumulative mass of all the granules. Based on this size distribution, Hwang et al. [29] proposed a precise analytical model for pyrotechnically actuated devices by investigating the combustion characteristics of ZPP charged in a small volume chamber. In most of the works, the impact of initiator metal cap, bridge wire, and grain size distribution and their sensitivity on the design of the device was not mentioned, which is, however, crucial for product development.

Targeting the effects on airbag inflator configurations, this work aimed at describing the complex function implemented in a pyrotechnic initiator. At first, the derivation of the numerical model was thoroughly discussed in sections 2 and 3. Due to the restriction in measuring the physical properties during deployment, the parameter calibration and model validation was carried out by comparing the pressure evolution in the closed bomb configuration as presented in Section 4.

The target of consistent coupling between simulation models for all the functional components in an airbag inflator enforces a step-by-step approach. Thus a cold gas inflator was selected as the first step system to connect initiator energy output with the shock wave generated in the stored gas, which is the design function of the inflator. In Section 5, the CFD software OpenFOAM was applied to capture the wave dynamics, and the modeling strategy and simulation results were discussed for the system.

A parameter sensitivity study was also conducted, where some performance control variables in the initiator and inflator design were selected and presented in each relevant section of applications. Based on the parametric study, an overview of the initiator ballistics and inflator functionality could be portrayed. This modeling and simulation strategy could widely contribute to design optimization and functional safety issues. Finally, a summary and concluding remarks are provided in the last, Section 6.

\section{Underlying Model Basis}

The main strategy to describe the thermal conditions during the initiator deployment requires the application of mass and energy conservation in individual systems as proposed in earlier studies [11]. In this section, considering the solid propellant as a thermal and chemical producer, the multicharge initiator configuration and its deployment in closed bomb test was described by the underlying transport equations. Figure 2 shows a simplified sketch of an initiator with solid grains loaded as a fuel-oxidizer combination. As already reported by Gonthier et al. [10] and Hsieh et al. [30], the products of the solid reactants $(s)$ after being activated by the burn out of bridge wire exist in gas $(g)$ and condensed phase $(l)$, and the changes in their thermodynamic states were obtained by the mass and energy conservation. 

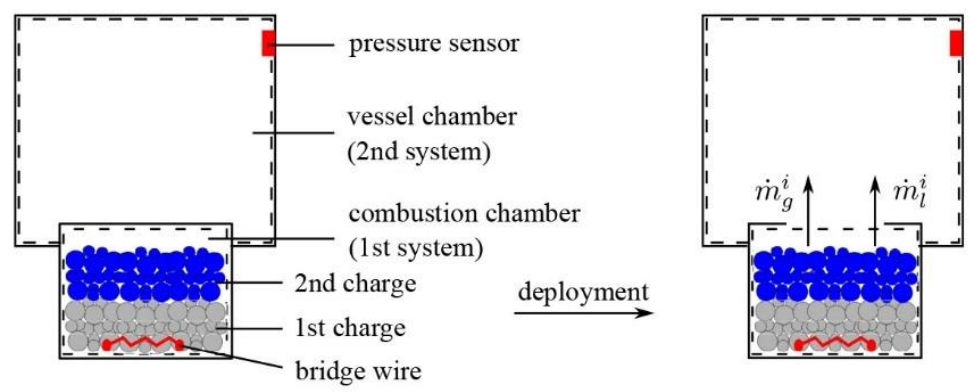

Figure 2 Sketch of initiator coupling with closed bomb vessel.

Three species are accounted for in every system: solid pyrotechnic reactants $(s)$, condensed (liquid) phase products $(l)$, and gas-phase products $(g)$. The solid pyrotechnic reactants are assumed to be confined in the initiator. In particular, the solid reactants consist of numerous non-uniform spherical grains. Mass and energy exchanges are permitted among species in the initiator. The thermal conductivity between the condensed and gas phases is assumed to be high enough such that the thermal equilibrium between these two phases can be attained instantaneously. Also, no mass transfer is allowed across the system boundary, while energy is transferred between the system and its surroundings. Spatial variations within the initiator are neglected; thus, all the variables are only time-dependent. Besides, the potential and kinetic energy of the solid reactants are neglected, and no chemical reaction occurs between the individual charges.

Since the fuel and oxidizer are premixed in the solid form, combustion of solid propellant occurs near the surface, where vaporization and decomposition take place. Thus, the burning regression could be described by Eq. (1),

$$
\frac{d V}{d t}=-A_{b} r_{b}
$$

where $V, A_{b}, r_{b}$ are the volume, burning surface area, and burn rate of the propellant, respectively.

\subsection{Mathematical Descriptions for Multi-charged Initiator Deployment in A Closed Vessel}

While dealing with multi-phase modeling, various methods, including Euler-Euler, Euler-Lagrange, or probability density function can be used (e.g., [31, 32]). In the present paper, an Euler-Euler approach was followed. Considering an initiator loaded with $M$ charges of different composites (see Figure 2), regardless of the initiator cap effects and the energy released from bridge wire, the mass, and energy conservation in the combustion chamber (1st system) of the $i^{\text {th }}$ charge according to the derivation mentioned in earlier studies [10] results in the following eqs.,

$$
\begin{gathered}
\frac{d}{d t}\left(\rho_{s}^{i} V_{s}^{i}\right)=-\rho_{s}^{i} A_{b}^{i} r_{b}^{i}, \\
\frac{d}{d t}\left(\rho_{l}^{i} V_{l 1}^{i}\right)=\eta_{l}^{i} \rho_{s}^{i} A_{b}^{i} r_{b}^{i}-\dot{m}_{l}^{i}, \\
\frac{d}{d t}\left(\rho_{g 1}^{i} V_{g 1}^{i}\right)=\left(1-\eta_{l}^{i}\right) \rho_{s}^{i} A_{b}^{i} r_{b}^{i}-\dot{m}_{g}^{i},
\end{gathered}
$$




$$
\begin{gathered}
\frac{d}{d t}\left(\rho_{s}^{i} V_{s}^{i} e_{s}^{i}\right)=-\rho_{s}^{i} e_{s}^{i} A_{b}^{i} r_{b}^{i} \\
\frac{d}{d t}\left(\rho_{l 1}^{i} V_{l 1}^{i} e_{l 1}^{i}\right)=\eta_{l}^{i} \rho_{s}^{i} e_{s}^{i} A_{b}^{i} r_{b}^{i}-h_{l 1}^{i} \dot{m}_{l}^{i} \\
-\frac{1}{2} \dot{m}_{l}^{i} u^{2}+\dot{Q}_{l 1}^{i}+E_{l}^{i}, \\
\frac{d}{d t}\left(\rho_{g 1}^{i} V_{g 1}^{i} e_{g 1}^{i}\right)= \\
-\frac{1}{2} \dot{m}_{g}^{i} u^{2}+\dot{Q}_{g 1}^{i}+E_{g}^{i},
\end{gathered}
$$

where $A_{b}^{i}$ and $r_{b}^{i}$ are the burning surface area and burn rate of the $i^{\text {th }}$ charge solid grain, respectively. $\eta_{l}^{i}$ is the mass fraction of condensed product. $h_{l 1}^{i}$ and $h_{g 1}^{i}$ are the enthalpy of condensed and gas phases. $e_{s}^{i}, e_{l 1}^{i}$, and $e_{g 1}^{i}$ are the internal energy of solid reactant, condensed phase, and gas-phase products. $\dot{Q}_{l 1}$ and $\dot{Q}_{g 1}$ denote the heat interaction between the reaction products and the system surroundings. The mass flow of gas and condensed phase were assumed to share the same flow speed $u$ while passing through the throat. $E_{l}^{i}$ and $E_{g}^{i}$ are the energy of the source/sink brought by external devices (e.g., bridge wire) into the condensed and gas phase.

The mass and energy conservation in the vessel chamber ( 2 nd system) of the $i^{\text {th }}$ charge can be given as

$$
\begin{gathered}
\frac{d}{d t}\left(\rho_{l}^{i} V_{l 2}^{i}\right)=\dot{m}_{l}^{i}, \\
\frac{d}{d t}\left(\rho_{g 2}^{i} V_{g 2}^{i}\right)=\dot{m}_{g}^{i} \\
\frac{d}{d t}\left(\rho_{l}^{i} V_{l 2}^{i} e_{l 2}^{i}\right)=h_{l 1}^{i} \dot{m}_{l}^{i}+\frac{1}{2} \dot{m}_{l}^{i} u^{2}+\dot{Q}_{l 2}^{i} \\
\frac{d}{d t}\left(\rho_{g 2}^{i} V_{g 2}^{i} e_{g 2}^{i}\right)=h_{g 1}^{i} \dot{m}_{g}^{i}+\frac{1}{2} \dot{m}_{g}^{i} u^{2}+\dot{Q}_{g 2}^{i} .
\end{gathered}
$$

The subscripts "1" and "2" in these equations were used to label quantities associated with the combustion chamber and the vessel, respectively. By applying geometric relations, Dalton's law, and the assuming calorically perfect gas product, the above equations could be simplified as

$$
\begin{gathered}
\frac{d V_{s}^{i}}{d t}=-A_{b}^{i} r_{b}^{i}, \\
\frac{d V_{l 1}^{i}}{d t}=\frac{\eta_{l}^{i} \rho_{s}^{i} A_{b}^{i} r_{b}^{i}-\dot{m}_{l}^{i}}{\rho_{l}^{i}}
\end{gathered}
$$




$$
\begin{aligned}
& \frac{d \rho_{g 1}^{i}}{d t}=\frac{\left\{\begin{array}{c}
\left(1-\eta_{l}^{i}\right) \rho_{s}^{i} A_{b}^{i} r_{b}^{i}-\dot{m}_{g}^{i} \\
+\rho_{g 1}^{i} \sum_{j=1}^{M}\left(\frac{d V_{s}^{j}}{d t}+\frac{d V_{l 1}^{j}}{d t}\right)
\end{array}\right\}}{V_{g 1}} \\
& \frac{d T_{1}}{d t}=\frac{\left\{+\sum_{i=1}^{M}\left\{\begin{array}{c}
\dot{Q}_{1}+E \\
\rho_{s}^{i} A_{b}^{i} r_{b}^{i}\left(e_{s}^{i}-e_{l 1}^{i} \eta_{l}^{i}-e_{g 1}^{i}\left(1-\eta_{l}^{i}\right)\right) \\
-\left(h_{l 1}^{i}-e_{l 1}^{i}\right) \dot{m}_{l}^{i}-\left(h_{g 1}^{i}-e_{g 1}^{i}\right) \dot{m}_{g}^{i} \\
-\frac{\left(\dot{m}_{l}^{i}+\dot{m}_{g}^{i}\right) u^{2}}{2}
\end{array}\right\}\right.}{\sum_{i=1}^{M}\left(\rho_{l}^{i} V_{l 1}^{i} c_{v_{l 1}}^{i}+\rho_{g 1}^{i} V_{g 1} c_{v_{g 1}}^{i}\right)} \\
& \frac{d V_{l 2}^{i}}{d t}=\frac{\dot{m}_{l}^{i}}{\rho_{l}^{i}} \\
& \frac{d \rho_{g 2}^{i}}{d t}=\frac{\dot{m}_{g}^{i}+\frac{\rho_{g 2}^{i} \sum_{j=1}^{M} d V_{l 2}^{j}}{d t}}{V_{g 2}} \\
& \frac{d T_{2}}{d t}=\frac{\sum_{i=1}^{M}\left\{\begin{array}{c}
\left(h_{l 1}^{i}-e_{l 2}^{i}\right) \dot{m}_{l}^{i}+\left(h_{g 1}^{i}-e_{g 2}^{i}\right) \dot{m}_{g}^{i} \\
+\frac{\left(\dot{m}_{l}^{i}+\dot{m}_{g}^{i}\right) u^{2}}{2}
\end{array}\right\}+\dot{Q}_{2}}{\sum_{i=1}^{M}\left(\rho_{l}^{i} V_{l 2}^{i} c_{v_{l 2}}^{i}+\rho_{g 2}^{i} V_{g 2} c_{v_{g 2}}^{i}\right)}
\end{aligned}
$$

where $V_{1}$ and $V_{2}$ are the volume of the initiator and the closed vessel, and

$$
\begin{gathered}
\dot{Q}_{1}=\sum_{i=1}^{M}\left(\dot{Q}_{l 1}^{i}+\dot{Q}_{g 1}^{i}\right), \\
\dot{Q}_{2}=\sum_{i=1}^{M}\left(\dot{Q}_{l 2}^{i}+\dot{Q}_{g 2}^{i}\right), \\
E=\sum_{i=1}^{M}\left(E_{l}^{i}+E_{g}^{i}\right) .
\end{gathered}
$$

Based on this formulation, the model of an initiator equipped with $M$ charges resulted in a total of $5 M+2$ governing equations.

\section{Modeling Issues Related to Initiator Complexity}

An industrial product often compromises with the realization and constrain of integrity, which is primarily not related to the product's main function. In the framework of a commercially used initiator, the model basis is not sufficient due to the complications. Hence, concerning a model 
which presents all the expected characteristics, further issues have to be investigated and modeled. These include propellant grain size distribution, the contribution of bridge wire and metal cap, and pyrotechnic burn rate to ensure the compatibility of each element within the underlying equation system.

\subsection{Grain Size Distribution}

Pyrotechnic materials used in the commercial initiators are fine particles, which support rapid chemical reactions by their large contact surfaces. The distribution of their granular sizes and contact areas could be formulated as probability density function (PDF), derived from the supplier's data in the form of cumulative distribution function (CDF).

\subsubsection{Initial Grain Size Determination}

From the manufacturing point of view, single chemical ingredients are acquired separately and then mixed as a pyrotechnic composite, where each element has its grain size and shape distributions. In this work, the Weibull function [33] was applied to obtain the CDF for each component. The Weibull distribution facilitates a better fit to the realistic grain conditions and is written as

$$
F(x)= \begin{cases}1-e^{-\left(\frac{x}{\eta}\right)^{\beta},} & x \geq 0 \\ 0, & x<0\end{cases}
$$

where $x$ is the diameter of solid grain, $\eta$ and $\beta$ are model constants determined via curve fitted to the incoming inspection.

By differentiating the CDF, the corresponding PDF is obtained as

$$
f(x)=\frac{\beta}{\eta}\left(\frac{x}{\eta}\right)^{\beta-1} e^{-\left(\frac{x}{\eta}\right)^{\beta}} .
$$

The mixing process merges two distributions into a compound representation. A surface area-based ratio $\alpha$ combines the two PDFs. Taking ZPP, for instance, the final distribution could be formulated as

$$
f(x)_{Z P P}=\alpha f(x)_{Z_{r}}+(1-\alpha) f(x)_{K_{C l O}} .
$$

Assuming that all the ZPP grains are spherical, the merging ratio $\alpha$ could be determined as follows: The volume of the zirconium grains $V_{Z_{r}}$ is given as

$$
V_{Z_{r}}=\frac{m_{Z_{r}}}{\rho_{Z_{r}}}
$$

and the nominal grain number of $Z_{r}$ granules, $N_{Z_{r}}$ could be calculated as

$$
N_{Z_{r}}=\frac{6 V_{Z_{r}}}{\pi d_{Z_{r}}^{3}},
$$


where $d_{Z_{r}}$ is the mean diameter of $Z_{r}$ grains. The nominal surface area of all the zirconium grains $\left(S_{Z_{r}}\right)$ is equal to

$$
S_{Z_{r}}=\pi d_{Z_{r}}^{2} N_{Z_{r}}
$$

Similarly, the nominal surface area of all the $\mathrm{KClO}_{4}$ grains $\left(S_{\mathrm{KClO}_{4}}\right)$ could be calculated. The merging ratio $\alpha$ is set as,

$$
\alpha=\frac{S_{Z_{r}}}{S_{Z_{r}}+S_{K C l O}} .
$$

By applying Eq. 24, the distribution of the composite, and single component in a ZPP regime are shown in Figure 3.

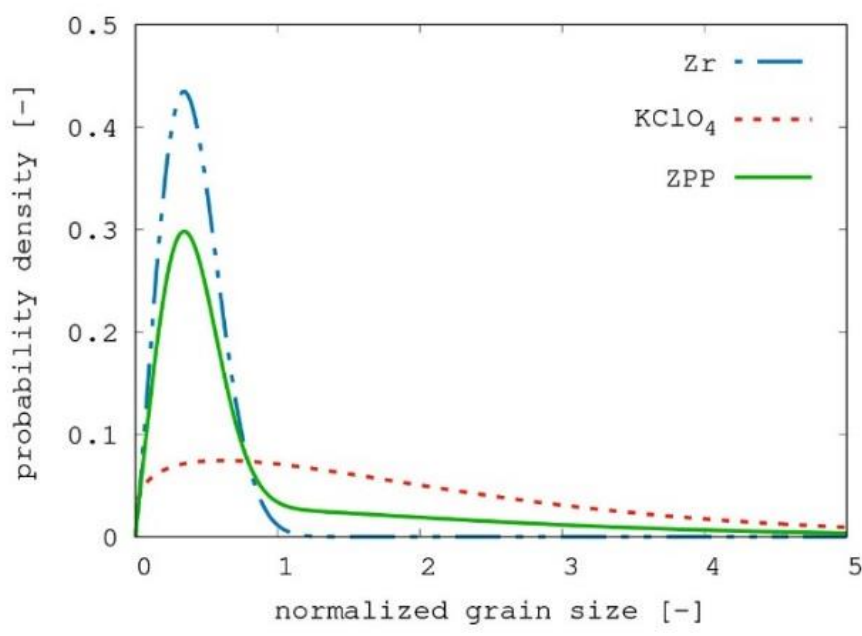

Figure 3 Initial grain size distribution of $Z_{r}, \mathrm{KClO}_{4}$, and the ZPP composite. The grain size axis $(x)$ was normalized by the mean grain size of the composite (ZPP).

\subsubsection{Dynamic Grain Size Distribution During Deployment}

The aforementioned method determines the initial state of grain size distribution. During the initiator deployment, all the grains participate in the combustion process with diminished grain volume. Also, the distribution varies dynamically with time. Numerical handling of the propellant with a prescribed PDF requires discretization of the smooth distribution into finite slices. Within each slice, the grain size is assumed to be identical, and its surface area can be calculated. During the combustion process, each slice is treated individually, including combustion products, and heat is released with the consumed solid propellant volume. The sum of all these physical properties serves as the contribution of the pyrotechnic composite in each time step. The distribution is assembled based on the new state after one iteration. Figure 4 shows the dynamics of the grain size distribution, where PDF was reduced significantly, and the distributed grain size range approached zero during evolution until the total propellant was consumed. 


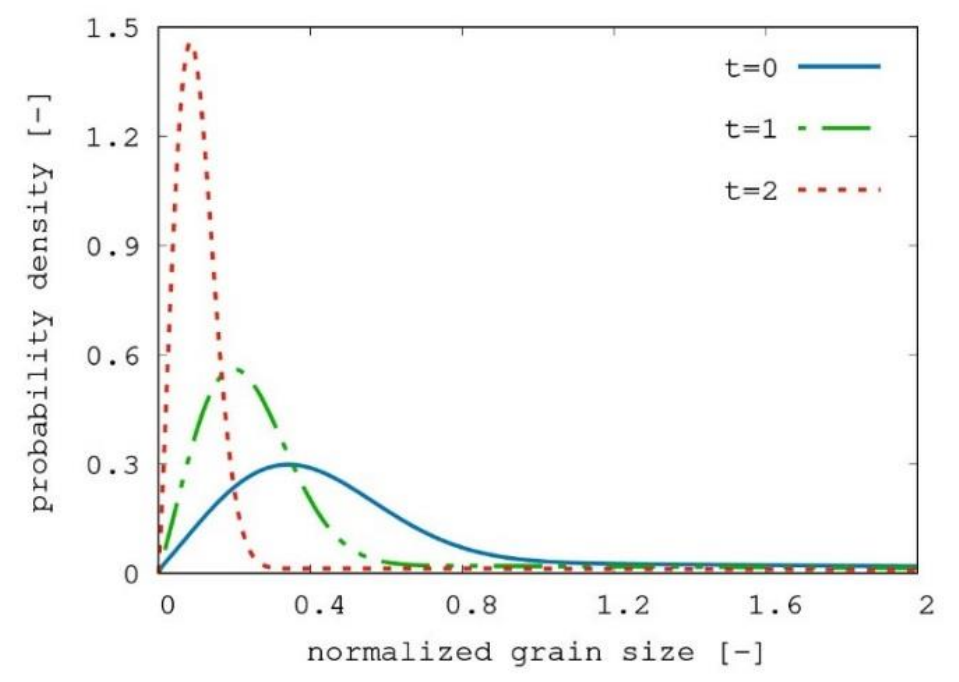

Figure 4 Dynamics of grain size distribution during deployment. The synthetic time step is applied, and the curve labeled with " $t=0$ " represents the initial PDF state.

\subsection{Energy Delivered from the Bridge Wire}

Bridge wire is the first component in the ignition process. On passing the electric current, the bridge wire is heated to a high-temperature level, activating the combustion of the attached composites by transferring heat to the pyrotechnic. The heat generation is mainly due to the electric resistance. Assuming that the heat is absorbed by the pyrotechnic, the energy input $E$ in Eq. 7 can be formulated to

$$
E=\int_{t_{0}}^{t_{B W B O}} I^{2}(t) \tilde{R}(t) d t
$$

where $t_{B W B O}$ is the bridge wire burn out time, $t_{0}$ is the initial time, $I(t)$ and $\tilde{R}(\mathrm{t})$ are the current and electric resistance.

The early phase pyrotechnic ignition via bridge wire is inhomogeneous and could not be obtained in the $\mathrm{OD}$ modeling regime. Meanwhile, the first pressure signal in the closed bomb test almost correlates to the bridge wire burn-out time (BWBO), which indicates a representative homogeneous combustion process after the complete contribution of the bridge wire. The corresponding modeling strategy for this phenomenon involves artificial suppression of the activated propellant surface within the early ignition phase. Besides, after BWBO, the entire propellant grains are taken into account.

\subsection{Impact of Initiator Metal Cap}

Initiator metal cap is present on the outer border of the initiator and is implemented for seal and protection purposes. From the ballistic point of view, the initiator metal cap is considered as a valve with pre-defined opening constrain, i.e., the system remains closed as long as the pressure inside the initiator is within the burst stress level. Once the pressure in the initiator exceeds the limit, the cap works as a convergent nozzle balancing the pressure in and outside of the initiator. 
The mass flow rate passing through the nozzle in the case of gaseous and condensed phase can be formulated by the Saint-Venant and Wantzel equation as follows,

$$
\dot{m}_{g}=\left\{\begin{array}{l}
\text { if } \frac{P_{2}}{P_{1}}>\left(\frac{2}{\gamma+1}\right)^{\frac{\gamma}{\gamma-1}}: \\
\rho_{1} A_{e} \sqrt{\gamma R T_{1}} \sqrt{\frac{2}{\gamma-1}\left(\left(\frac{P_{2}}{P_{1}}\right)^{\frac{2}{\gamma}}-\left(\frac{P_{2}}{P_{1}}\right)^{\frac{\gamma+1}{\gamma}}\right)} \\
\text { else : } \\
\rho_{1} A_{e} \sqrt{\gamma R T_{1}} \sqrt{\left(\frac{2}{\gamma+1}\right)^{\frac{\gamma+1}{\gamma-1}}} \\
\dot{m}_{l}=\frac{\eta_{l}}{1-\eta_{l}} \dot{m}_{g}
\end{array}\right.
$$

where $A_{e}$ is the cross-section area of the initiator, and $R$ is the specific gas constant.

\subsection{Representation of Burn Rate $\left(r_{b}\right)$ for Targeting Pyrotechnic Composites: ZPP and THPP}

In Eq. (12), the burn rate $r_{b}$, at which the mass is transferred from solid reactants to gas and condensed phase products is modeled via Vieille's law [34] and is given by Eq. (28),

$$
r_{b}=a P^{n}
$$

This equation relates the burning velocity $\left(r_{b}\right)$ normal to each infinitesimal burning surface to the surrounding pressure $(P)$ with the material constants $a$ and $n$ that need to be evaluated.

However, this expression is independent of the reactant's initial temperature, which is not consistent with the fundamental description of the Arrhenius equation. Moreover, Vieille's law assumption leading to the identical ballistic performance by varying the conditioned temperature does not hold. Although several models have been proposed to address this issue [35, 36], no promising conclusion could be made so far [37]. In the present work, the evaluation was based on Vieille's law and carried out at different preconditioned temperature levels depending on the available measurement data.

ZPP and THPP were selected as the pyrotechnics in this work. Even though the burn rate parameters of these two composites have been largely investigated [11,38], the current work refocused on the available measuring data and evaluated the validity of the above-mentioned modeling strategies in comparing to the burn rate information in the literature.

\subsubsection{Zirconium Potassium Perchlorate (ZPP)}

Data for burn rate parameter evaluation were acquired in the closed bomb test comprised of opened initiators loaded with $35 \mathrm{mg}$ of ZPP, deployed at three preconditioned temperatures $\left(-40^{\circ} \mathrm{C}\right.$, 
$23^{\circ} \mathrm{C}$, and $105^{\circ} \mathrm{C}$. Pressure evolutions in the $10 \mathrm{ccm}$ vessel were documented for numerical validation. As shown in Figure 5 a, one-system single charge-based equations could be formulated for the numerical approach. The thermal properties of the ZPP composite during the chemical reaction under the corresponding weight combination were calculated using a NASA-based PEP algorithm [39], as well as the corresponding grain size distribution is implemented according to the provided incoming goods inspection. The best-fit burn rate parameters corresponding to the pressure evolution at each temperature level demonstrated a promising result compared to the literature $[10,11]$ and are shown in Table 1.

(a)

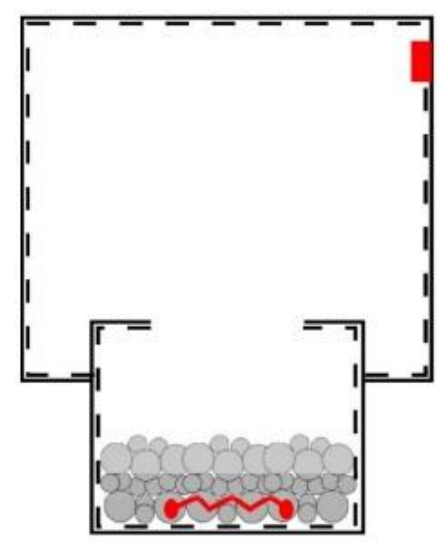

Figure 5 Evaluation of ZPP burn rate via a generic test configuration at diverse conditioned temperature levels. (a) Illustration of test configuration for evaluating ZPP burn rate and (b) ZPP burn rate evaluation at different preconditioned temperature levels.

Table 1 ZPP burn rate, $a$, and $n$ as Vieille's law parameters.

\begin{tabular}{lllll}
\hline Parameter & Unit & $105{ }^{\circ} \mathrm{C}$ & $23{ }^{\circ} \mathrm{C}$ & $-40{ }^{\circ} \mathrm{C}$ \\
\hline$a$ & $(\mathrm{MPa})^{-n} \cdot \mathrm{mm} / \mathrm{s}$ & 11.538 & 9.660 & 8.655 \\
$n$ & - & 0.79 & 0.80 & 0.79 \\
\hline
\end{tabular}

\subsubsection{Titanium Hydride Potassium Perchlorate (THPP)}

Furthermore, initiators with similar configurations were deployed to obtain the burning characteristics of THPP. Here, $100 \mathrm{mg}$ THPP was used as the secondary charge on top of $35 \mathrm{mg}$ of ZPP, as shown in Figure 6a. The corresponding governing equations were expanded for the configuration of a single system with two charges, and all the thermal properties were calculated by the PEP code, whereas the burn rate characteristics of ZPP were taken from the previous evaluation results. The best-fit burn rate parameters of THPP at all the three temperature levels are shown in Table 2, and a corresponding quantitative agreement with the data provided by Holy [38] could be seen in Figure 6b. 
Table 2 THPP burn rate, $a$, and $n$ as Vieille's law parameters.

\begin{tabular}{lllll}
\hline Parameter & Unit & $105^{\circ} \mathrm{C}$ & $23^{\circ} \mathrm{C}$ & $-40{ }^{\circ} \mathrm{C}$ \\
\hline$a$ & $(\mathrm{MPa})^{-n} \cdot \mathrm{mm} / \mathrm{s}$ & 21.62 & 20.78 & 19.57 \\
$n$ & - & 0.48 & 0.47 & 0.47 \\
\hline
\end{tabular}

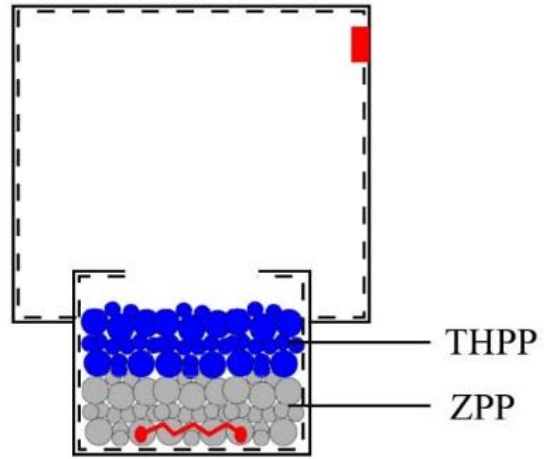

(a)

Figure 6 Evaluation of THPP burn rate via a generic test configuration at diverse conditioned temperature levels. (a) Illustration of test configuration evaluating THPP burn rate; (b) THPP burn rate evaluation at different preconditioned temperature levels.

\section{Validation of Initiator Model in Closed Vessel Tests}

To understand the initiator ballistics correctly, closed vessel tests were considered as the first platform examining the validity of the numerical model. ZPP based double-charged initiators were taken as the target configuration, and the equation system of 12 ODEs with the above-mentioned modeling strategies corresponding to the realistic initiator integrity was formulated. A sensitivity study was conducted along with the model validation. The steering product design parameters were varied based on the discussion about the corresponding ballistic impact and the actual possible scenarios in the product development phase.

\subsection{Numerical Evaluation of the Initiator Ballistics}

The targeting initiator was equipped with two charges and $300 \mathrm{mg}$ of ZPP, distinguished by different mixing weight ratios of $\mathrm{Zr}$ and $\mathrm{KClO}_{4}$ in each charge. The primary charge was implemented with $50 \mathrm{mg}$ of $50 \% \mathrm{Zr}$ and $50 \% \mathrm{KClO}_{4}$, while $250 \mathrm{mg}$ of $57.5 \% \mathrm{Zr}$ and $42.5 \% \mathrm{KClO}_{4}$ were used in the secondary charge. The bridge wire was applied with its burn-out time of around $0.35 \mathrm{~ms}$. The chemical composites were closed in a metal cap with limited stress of 150 bar correlated to its maximum mechanical strain.

Initiators were preconditioned at $-40^{\circ} \mathrm{C}, 23^{\circ} \mathrm{C}$, and $105^{\circ} \mathrm{C}$ according to the product development specification [40]. Deployment of the initiators took place in a $10 \mathrm{ccm}$ vessel, measuring the pressure for numerical validation. 


\subsubsection{Calculation Procedure}

According to the conditions mentioned above, a 12-ODE based equation system was formulated. Thermal data of the chemical composite in each charge were calculated by PEP, where the internal combustion energy and specific heat capacity of the chemical product were considered constants for the combustion properties. It was interesting to see that these values varied from charge to charge, even though all the generants were ZPP based composites.

The corresponding modeling parameters, including the grain size distribution of zirconium and potassium perchlorate, the bridge wire resistance and burn-out time, and the stress limit for the initiator cap, were obtained. The burn rate parameters for both charges were assumed to be identical. Also, the $10 \mathrm{ccm}$ vessel was designated with the heat conduct coefficient of $1000 \mathrm{~J} /\left(\mathrm{K} \cdot \mathrm{m}^{2}\right)$. The calculations were carried out at all the three preconditioned temperature levels already mentioned, and all the settings were kept identical except the conditioned temperature-dependent burn rate parameters. Euler explicit method was utilized for the temporal approximation with a time step of $1.67 \times 10^{-7} \mathrm{sec}$ to ensure the convergence of the numerical results (Figure 7).

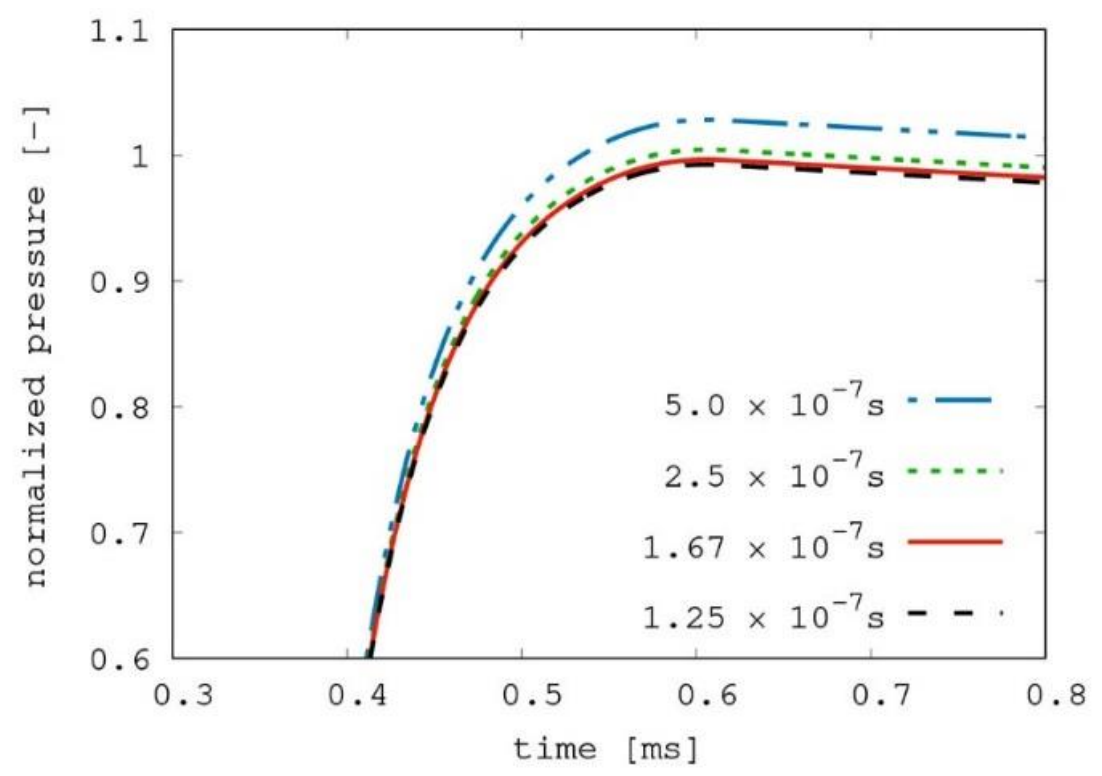

Figure 7 Time step convergence study. Evolutions shown in vessel pressure were normalized by the peak value of the selected time step results.

\subsubsection{Modeling Results}

Figure 8 shows the comparison of the pressure level in the vessel with the measured data, exhibiting a quantitative agreement between all three temperature levels. In particular, the maximal peak pressure indicated competent thermodynamic data of the chemical composites generated by PEP incorporated with the equation system. Also, the pressure was reduced after the pressure peak demonstrated a realistic estimation of heat loss parameter in the closed bomb configuration. 


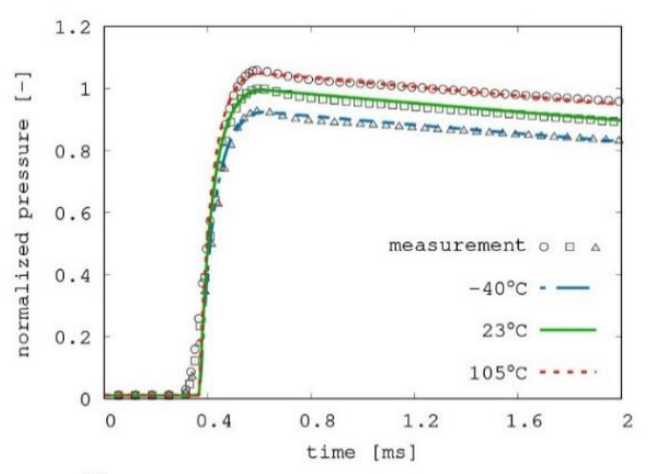

(a)

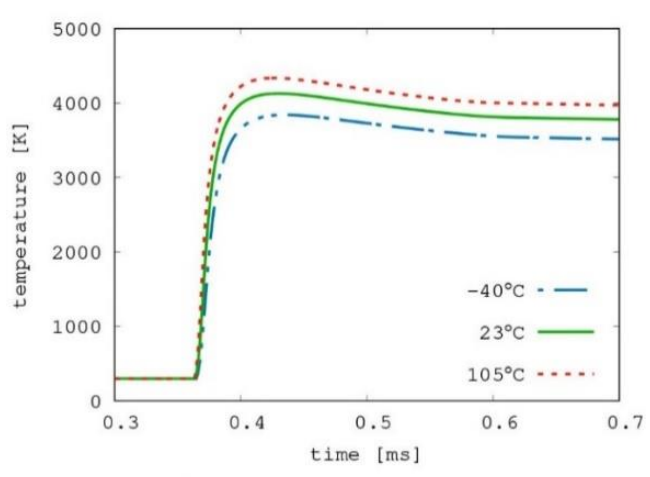

(b)

Figure 8 Validation of physical properties in closed bomb tests at different preconditioned temperature levels. Values normalized by the measured pressure peak at ambient temperature level. (a) Pressure evolution in the vessel. $\triangle, \square, \odot$ : mean of pressure measurement data under preconditioned temperature low $\left(-40^{\circ} \mathrm{C}\right)$, ambient $\left(23^{\circ} \mathrm{C}\right)$ and high $\left(105^{\circ} \mathrm{C}\right)$ levels; (b) Temperature evolution in the vessel.

A relatively smooth increase in the pressure measurement was not observed in the numerical solution; instead, deviations were seen between 0.38 to $0.41 \mathrm{~ms}$. Pressure observed in numerical results showed a certain delay in the initial signals but had a fast flushing evolution to the peak value. The probable reason behind this deviation could be the inconsistency between BWBO and the first pressure signal in the vessel or a too low-rated activation surface set within the BWBO time. Such circumstances led to weaker combustion in the model than in reality. Thus, a longer time is needed to achieve the bursting pressure level for the cap. Another possibility might include too early cap opening, resulting in the crack formation in the cap before the ideal bursting pressure is attained. This corresponded to a lower pressure level in the initiator while the cap was still opened. Thus the low mass and energy flow out of the initiator resulted in a smooth raise in the vessel pressure evolution.

Figure 9 shows the pressure and temperature evolution in the initiator during combustion. The high-temperature level indicated a large amount of energy released from the pyrotechnic composites approaching chemically defined combustion temperature contradictory to the heat loss. The resulting high temperature led to a high-pressure level with the equation of state.

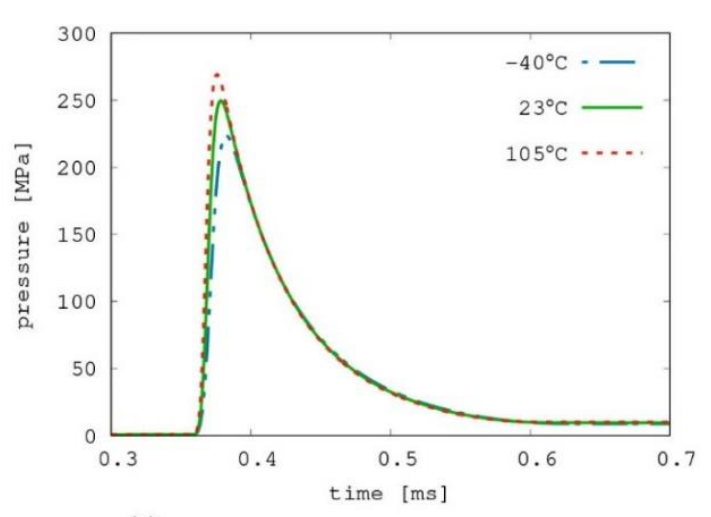

(a)

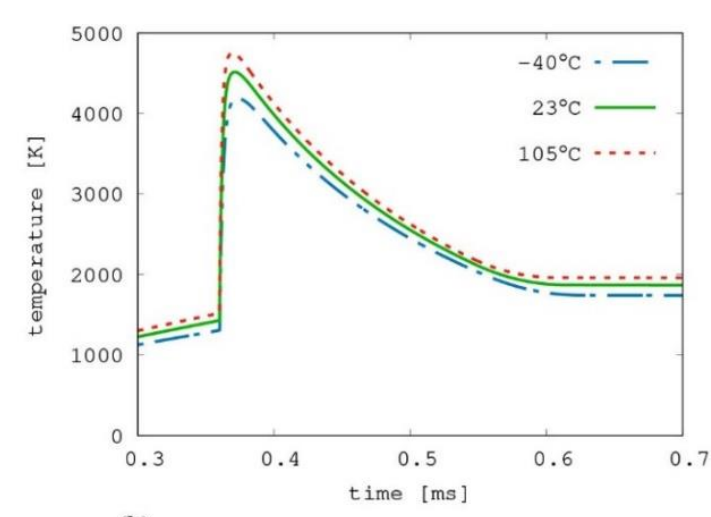

(b)

Figure 9 Initiator characteristics during closed bomb test at different preconditioned temperature levels. (a) Pressure and (b) temperature evolution in the initiator. 
To compensate for the pressure level between the initiator and the vessel, the cross-section on the initiator served as a convergent nozzle through which the mass and energy transfer occurred (Figure 10). The spread of physical properties from high to low preconditioned temperature was correlated to the applied burn rate parameters, where faster burning resulted in the higher temperature and pressure in the initiator while the contribution from the heat loss remained constant. The corresponding higher peak value of the mass and energy transfer rate is shown in Figure 10.

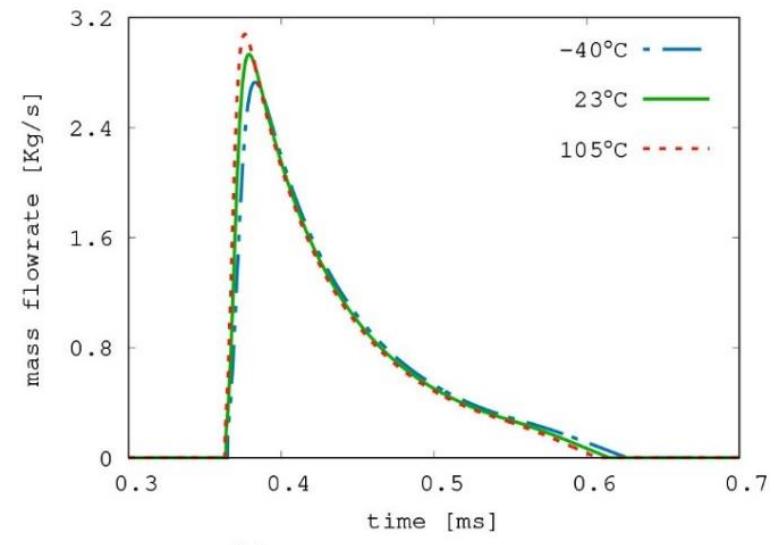

(a)

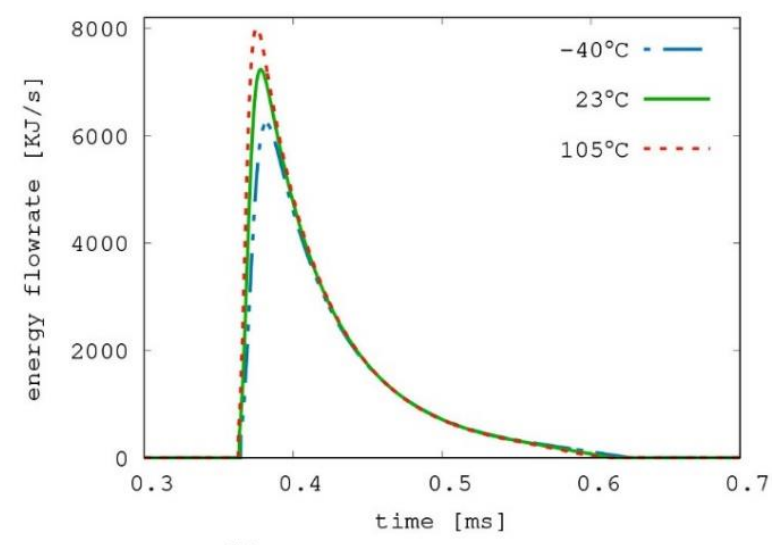

(b)

Figure 10 (a) Mass and (b) energy transfer rates through initiator cap port to vessel.

In reality, these phenomena might not take place exactly as they are modeled. Since the metal cap cannot sustain such high temperature and pressure, a perfect breakage with the defined crosssection is barely possible. Instead, the metal husk could be demolished. Nevertheless, the numerical method reproduces the dynamics during the initiator deployment and provides a fair platform to discuss initiator ballistic performance.

\subsection{Sensitivity Study of Initiator Components Concerning Its Ballistics}

For a deeper understanding of the componential functionality in an initiator, the impact of maximum burst pressure of the initiator cap and the mixing ratio of zirconium and potassium perchlorate composite on the initiator ballistics was studied.

\subsubsection{Bursting Pressure of the Initiator Cap}

As described in section 3, the initiator cap protects the pyrotechnic composite from outer damage and humidity, for which a hard husk is mainly conceived. On the other hand, the initiator cannot complete its function without breaking the cap. Figure 11 depicts the probable impact of different stress levels with regards to the cap bursting on the pressure. The results showed that the harder the cap, the higher the delay in the signal and the steeper the pressure raised in the vessel. 


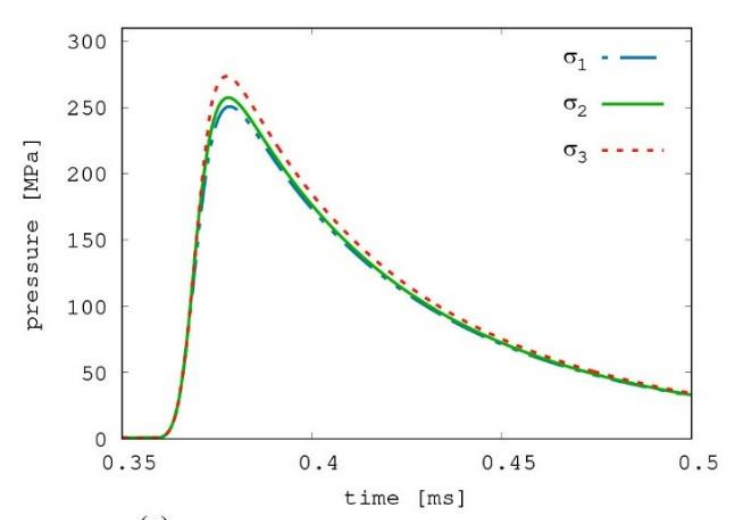

(a)

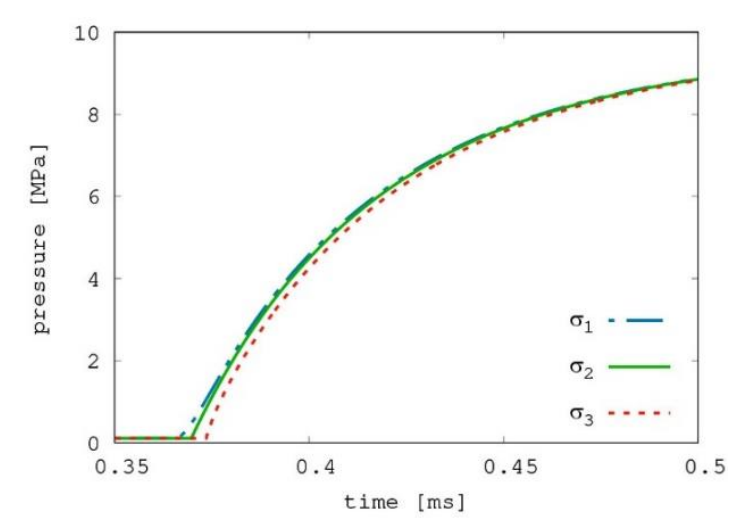

(b)

Figure 11 Pressure evolution in initiator (a) and vessel (b) at different cap stress levels. $\sigma_{1}=50 \mathrm{MPa}, \sigma_{2}=150 \mathrm{MPa}, \sigma_{3}=250 \mathrm{MPa}$.

The observed results could be interpreted as the following: the higher the limiting stress set for the cap, the longer the time taken by the chemical reaction to achieve the pressure level. Once the cap is broken, the mass and heat flux are activated to compensate for the pressure difference between the initiator and vessel systems. Right before the breaking of the cap, the one with the higher cap stress has a higher pressure level in the initiator, hence a higher burning rate according to Vieille's law (Eq. 28). Thus, the peak pressure in the initiator system attains a higher level than the one with lower cap stress, and the pressure slope in the vessel is correspondingly steeper, as observed in Figure 11a.

However, in the objective initiator loaded with $300 \mathrm{mg}$ of pyrotechnic, the effects were barely visible in the numerical solution. Since the propellant amount was large, the default pressure of 150 bar necessary for cap rupture would be rather easy to achieve, i.e., less amount of pyrotechnic would be applied; hence, the impact of the bursting strain on the initiator ballistics would also be higher.

Concerning the product development, the early burst of the initiator could lead to some unfavored effects due to which the unburnt propellant grains could be expelled out of the initiator system. As long as the propellant is located outside the combustion system, it does not matter if it burns or not; rather a high deviation in the ballistic performance would be expected. Though, this issue could not be addressed in this work since the chemical reaction was assumed to stay in the initiator and consumed. Besides, it was not possible to further infer a result within this modeling framework.

\subsubsection{Sensitivity of Zirconium and Potassium Perchlorate Ratio}

Propellant mixing behavior has a crucial effect on the initiator ballistics as the ratio directly determines the reaction product and energy released. Figure 12 summarizes the combustion energy of different $\mathrm{Zr}$ to $\mathrm{KClO}_{4}$ ratios evaluated by the PEP. The results showed that by increasing the amount of potassium perchlorate (or reducing the zirconium content), the release of combustion energy also increases. This release of energy reaches a maximum at a certain $\mathrm{Zr} / \mathrm{KClO}_{4}$ ratio and decreases beyond it. Though, the survey could not be proceeded due to the singularity in the calculation. 


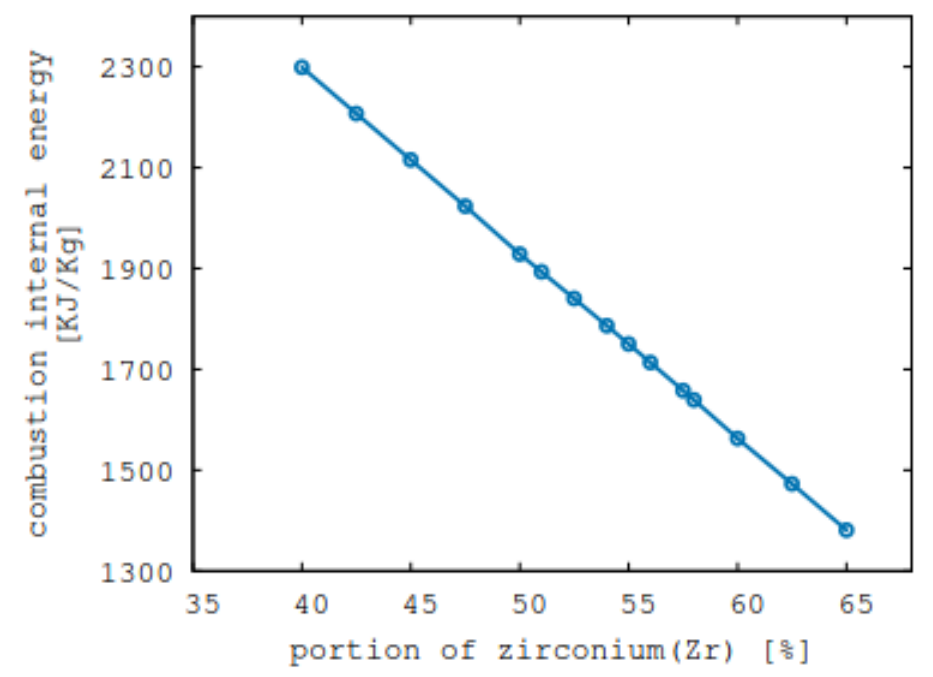

Figure 12 Internal combustion energy at different composite mixing ratios (ZPP).

The physical interpretation behind the yield indicated that the higher energy was released during the chemical reaction in more efficient composite mixing behavior, attaining the maximum value at the stoichiometric ratio. Composites with the most efficient mixing ratio resulted in the higher temperature and pressure level in the combustion system (Figure 13) and followed a higher mass and energy flow rate transfer from the initiator. Consequently, a higher pressure level was expected in the vessel, as observed in Figure 14.

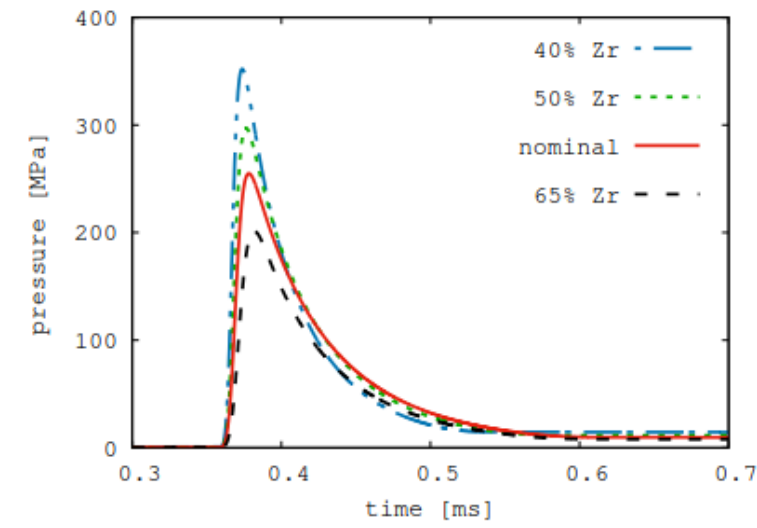

(a)

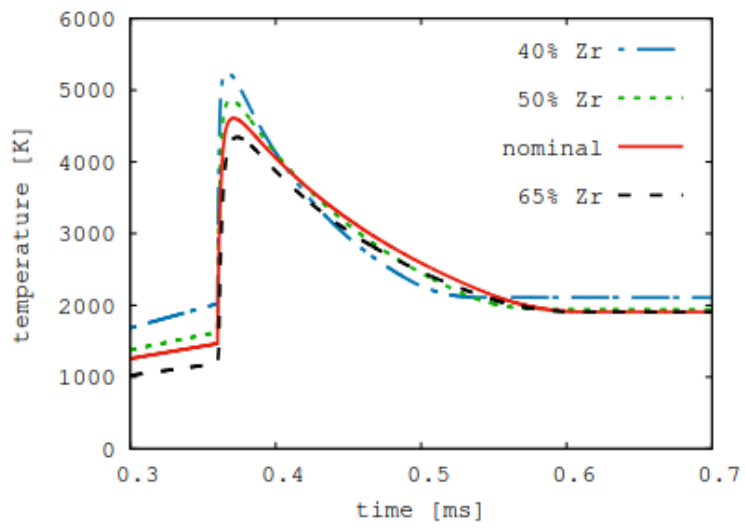

(b)

Figure 13 Results of the parameter study: evolution of physical properties in the initiator at different composite mixing ratios at the secondary charge. (a) Pressure and (b) temperature evolution in the initiator. 


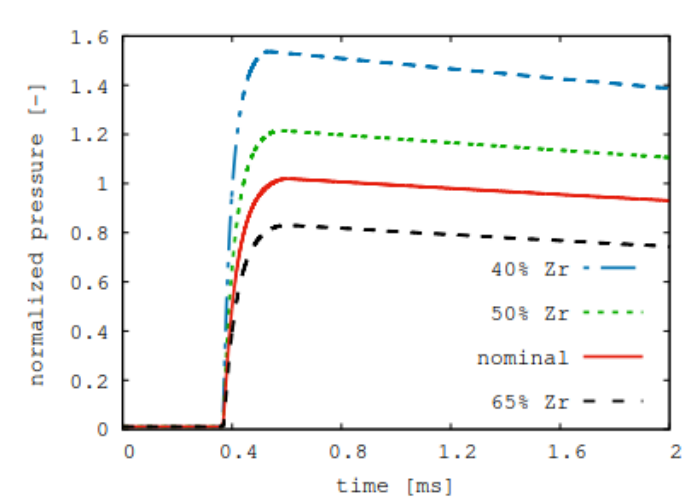

(a)

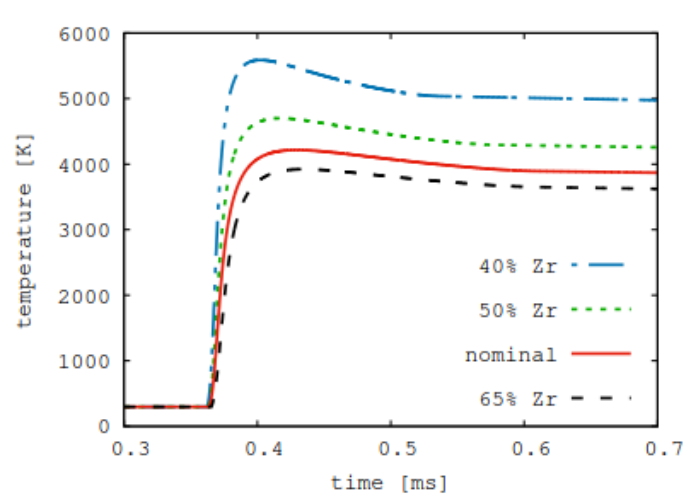

(b)

Figure 14 Results of parameter study: evolution of physical properties in the vessel at different composite mixing ratios. (a) Pressure and (b) temperature evolution in the vessel.

In reality, filled propellant grains in primary and secondary charges could hardly be burnt simultaneously and homogeneously, which was neither covered nor mirrored in the modeling strategy of this work. However, the composite mixing behavior related to thermal-chemical properties did reveal some information about the product development of the multi-charging initiators.

The purpose of developing a multi-charge initiator was to apply the easy-to-burn material in the primary charge to boost the ignition in the secondary charge, for which a high temperature and a large amount of condensed phase are always favored. The enhancement of the primary charge by adapting the composite mixing behavior might lead to a more stable chemical reaction of the main propellant charge and reduce the deviation in initiator ballistics. Thus, the issue of composite mixing is a matter of concern for both the maximum pressure level and the product quality in their ballistic performance.

\section{Initiator Impact on the Inflator Performance}

The utilization of initiators in the airbag framework is related to the inflator design, which requires ignition features to ensure stable inflator deployment. In this section, a cold gas inflator was selected as the targeting inflator, depicting the release of stored inert gases (e.g., Ar and $\mathrm{He}$ ) into the airbag system as the main mechanism of the action.

Figure 15 shows a sketch of the cold gas inflator, where mixed gases were filled and sealed in the container. An adaptor with a nozzle inside was assembled in the container and separated by the outlet membrane. On the other side, the initiator was applied and closed by the inlet membrane in the housing region. 


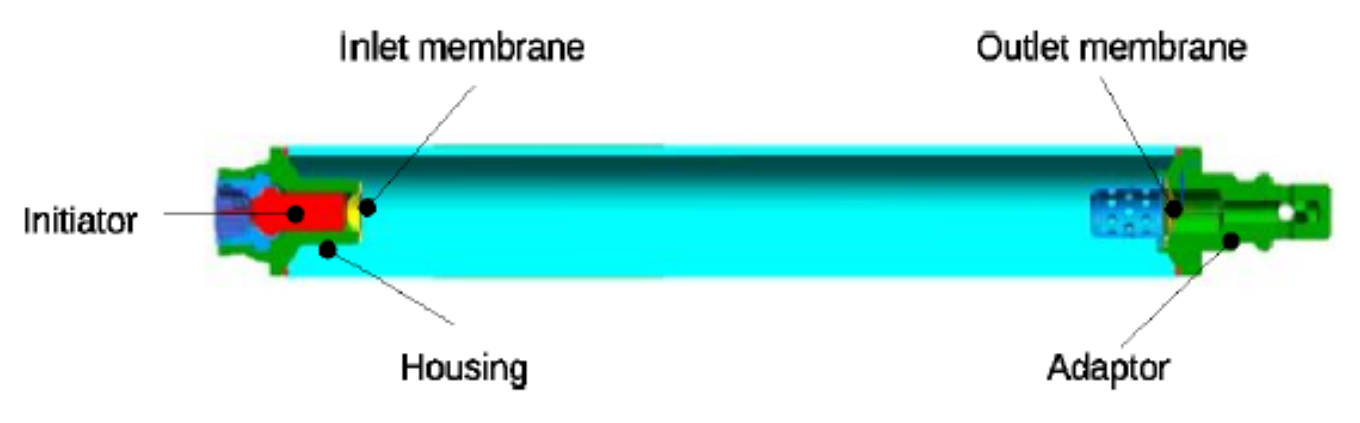

Figure 15 Sketch of a cold gas inflator.

When the initiator deploys, hot gases and condensed phase products fill into the housing region, increasing the pressure level. As the pressure on the inlet membrane exceeds the maximum strain limit of the membrane material, the membrane breaks down. The breakage and the pressure difference between the housing and container creates a shock, propagating along the axial direction toward the outlet membrane. Once the membrane on the outlet valve is hit by the shock and eventually breaks, the mixed gases flow through the valve, and inflation takes place. However, the outlet membrane must experience a sufficient level of shock to ensure a correct opening, being a crucial part of the designed function. This feature is related to the initiator ballistics, incorporated with the inflator ignition chain design.

\subsection{The ZPP-THPP Initiator}

The targeted initiator for this application was loaded with $770 \mathrm{mg}$ of the ZPP-THPP mixture, out of which $35 \mathrm{mg}$ of ZPP and $735 \mathrm{mg}$ of THPP were applied in the primary and secondary charge, respectively. The validation of the initiator model was carried out in a $40 \mathrm{ccm}$ vessel with the initiators deployed at $-40{ }^{\circ} \mathrm{C}, 23{ }^{\circ} \mathrm{C}$, and $105^{\circ} \mathrm{C}$ with corresponding burn rate parameters and thermal-chemical properties calculated by PEP. Pressure evolution in the vessel was compared with the measurement data, as shown in Figure 16. The results showed slight irregularities between the calculated and measurement results, especially in the time scale right after when the pressure curves reached the peak value. A steeper drop in the measurement data was observed in the deployments at all three preconditioned temperatures. This indicated a rapid change of heat loss and might relate to the gas flow movement inside the vessel, as not captured in the OD modeling scope. The slight discrepancy in the peak pressure values might refer to the non-identical setups of the calculation, such as the exact mixing behavior of THPP, the weight of pyrotechnics, and the dimensional tolerances of the measuring equipment. Nevertheless, these points were negligibly considered while assessing the inflator functionality. whereas a quantitative agreement was taken into account. 


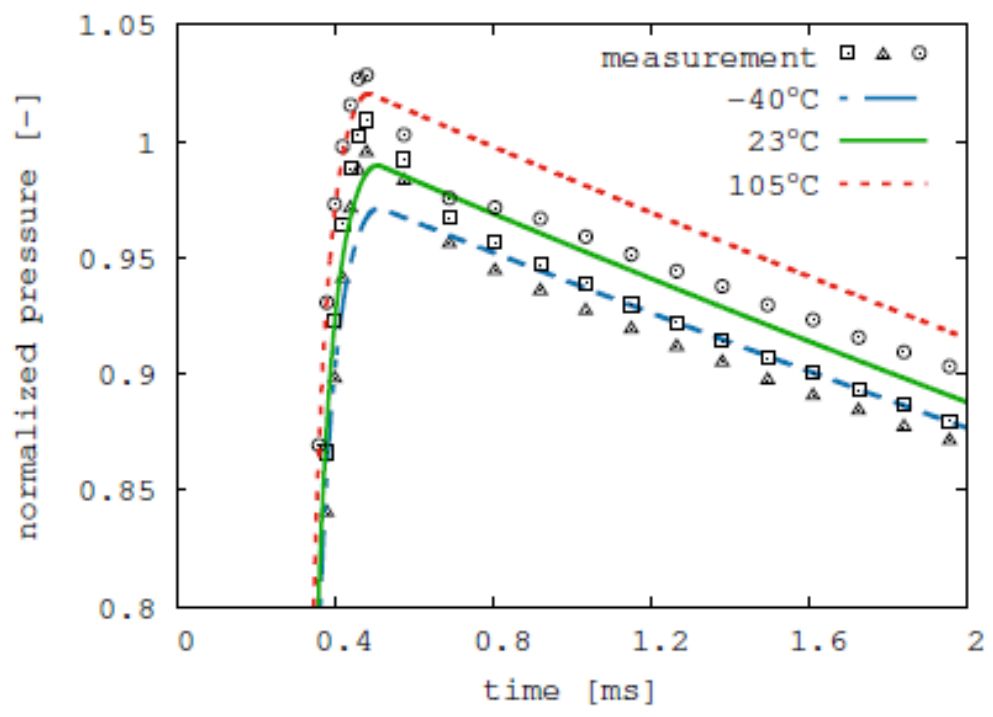

Figure 16 Validation of ZPP-THPP based initiator deployment in a $40 \mathrm{ccm}$ closed bomb. The pressure levels were normalized by the measured peak value at the ambient temperature deployment. $\triangle, \square, \odot$ : mean of pressure measurement data under preconditioned temperature at low $\left(-40^{\circ} \mathrm{C}\right)$, ambient $\left(23^{\circ} \mathrm{C}\right)$, and high $\left(105^{\circ} \mathrm{C}\right)$ levels.

Figure $17 \mathrm{~b}$ shows the temperature evolution in the combustion system with a maximum temperature less than that of the pure ZPP initiator (Figure 9b), even though the loading was much stronger than the ZPP ones as investigated in the previous section. This phenomenon was mainly due to the thermal-chemical properties of the composite represented in the combustion temperature, where THPP generally burns in a lower temperature range. Moreover, the highpressure level was not explicitly related to the high-temperature level.

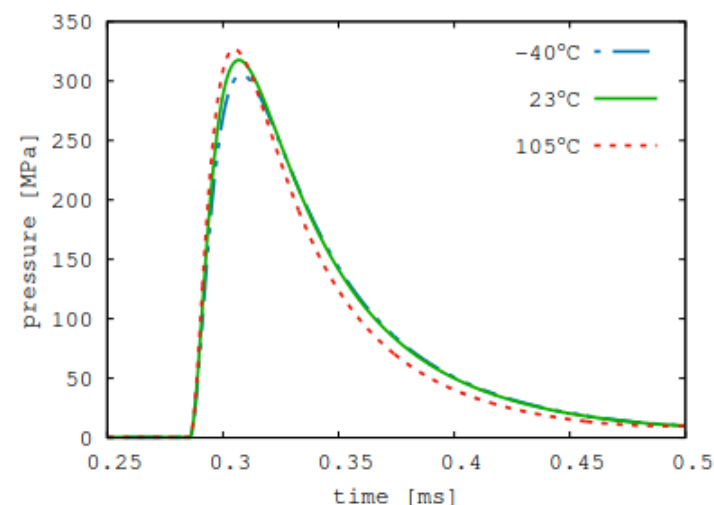

(a)

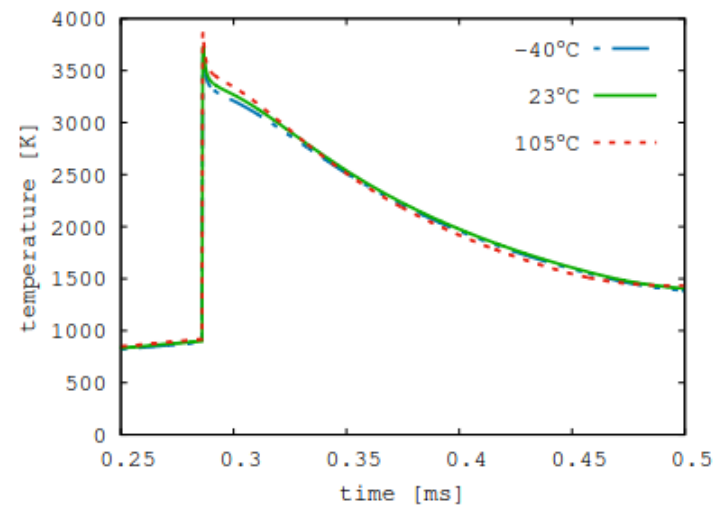

(b)

Figure 17 Evolution of physical properties and deployment of the ZPP-THPP based initiator. (a) Pressure and (b) temperature evolution in the initiator.

\subsection{Ignition Chain Modeling of the Cold Gas Inflator}

As shown in Figure 15, the initiator was enclosed by the inlet membrane in the housing region comprised of the initiator and the housing, and the inlet membrane that could be considered as the 
ignition chain assembly. The underlying mechanism behind this observation could be explained as follows: once the pressure level within the housing region exceeds the defined maximum stress of the inlet membrane, the membrane bursts. The initiator performance, housing volume, and equivalent stress representing the maximum membrane strain are the design parameters of the ignition chain configuration.

Based on this concept, the modeling of the ignition chain mechanism was similar to that of the closed bomb applications. Briefly, instead of a solid vessel collecting the heated gases and condensed phase products, the domain was opened by a given pressure correlating the maximum strain of the inlet membrane as the modeling strategy of the initiator cap. Once the membrane bursts, the gas and the energy flow through the defined housing area into the inflator, causing a drop in the pressure in the housing region (Figure 18). The corresponding modification for the 2 nd system (housing) in the governing equation yields:
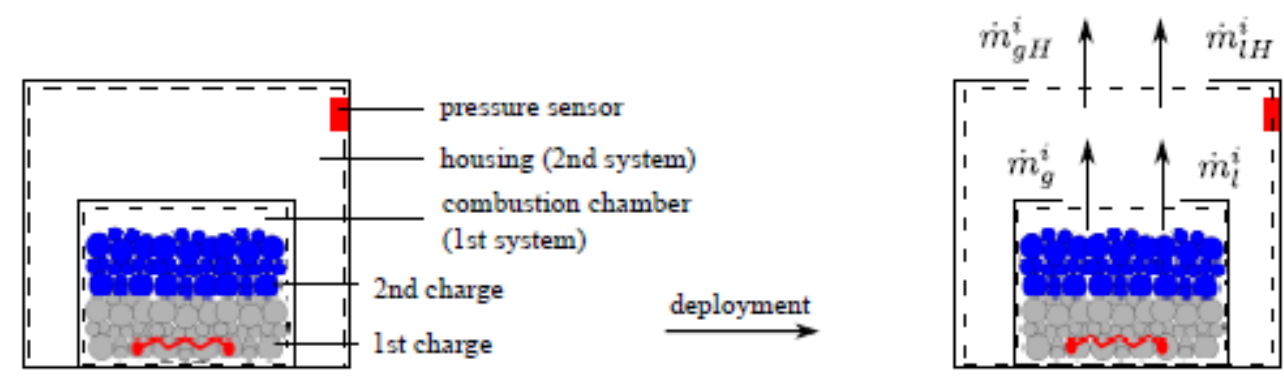

Figure 18 The modeling concept of initiator deployment in the inflator housing region.

$$
\begin{aligned}
& \frac{d V_{l 2}^{i}}{d t}=\frac{\dot{m}_{l}^{i}-\dot{m}_{l H}^{i}}{\rho_{l}^{i}} \\
& \frac{d \rho_{g 2}^{i}}{d t}=\frac{\dot{m}_{g}^{i}-\dot{m}_{g H}^{i}+\frac{\rho_{g 2}^{i} \sum_{j=1}^{M} d V_{l 2}^{j}}{d t}}{V_{g 2}} \\
& \frac{d T_{2}}{d t}=\frac{\sum_{i=1}^{M}\left\{\begin{array}{c}
\left(h_{l 1}^{i}-e_{l 2}^{i}\right) \dot{m}_{l}^{i}+\left(h_{g 1}^{i}-e_{g 2}^{i}\right) \dot{m}_{g}^{i} \\
-\left(h_{l 2}^{i}-e_{l 2}^{i}\right) \dot{m}_{l H}^{i} \\
-\left(h_{g 2}^{i}-e_{g 2}^{i}\right) \dot{m}_{g H}^{i}+\frac{\left(\dot{m}_{l}^{i}+\dot{m}_{g}^{i}\right) u^{2}}{2} \\
-\frac{\left(\dot{m}_{l H}^{i}+\dot{m}_{g H}^{i}\right) u_{H}^{2}}{2}
\end{array}\right\}+\dot{Q}_{2}}{\sum_{i=1}^{M}\left(\rho_{l}^{i} V_{l 2}^{i} c_{v_{l 2}}^{i}+\rho_{g 2}^{i} V_{g 2} c_{v_{g 2}}^{i}\right)}
\end{aligned}
$$

where $\dot{m}_{g H}^{i}, \dot{m}_{l H}^{i}$ are the mass fluxes at the port of housing and $u_{H}$ is the corresponding fleeing velocity. Equation (12)-(15) and Equation (29)-(31) are the governing equation system.

\subsubsection{Validation of Ignition Chain Features}

Figure 19 shows the pressure evolution in the housing region obtained by the numerical method. In comparison to the measurement data, the numerical results validated the applied parameters. 
The scattered measuring data exhibited a large deviation in the membrane bursting pattern, and the non-identical material characteristics of the membrane in a highly dynamic condition or the uncertainties in the measured data were speculated. Besides, the membrane burst mechanism in the model was represented by a single pressure level, acquired individually by the burst test of the isolated parts. The structural simulations incorporated with different anisotropic raw materials possessing varied welding properties could be conducted to explore material complexity and find the root cause behind the deviations observed in the measurement data. However, this would relate to the detailed investigation of material requirements and assembling techniques, which is out of the scope of this work.

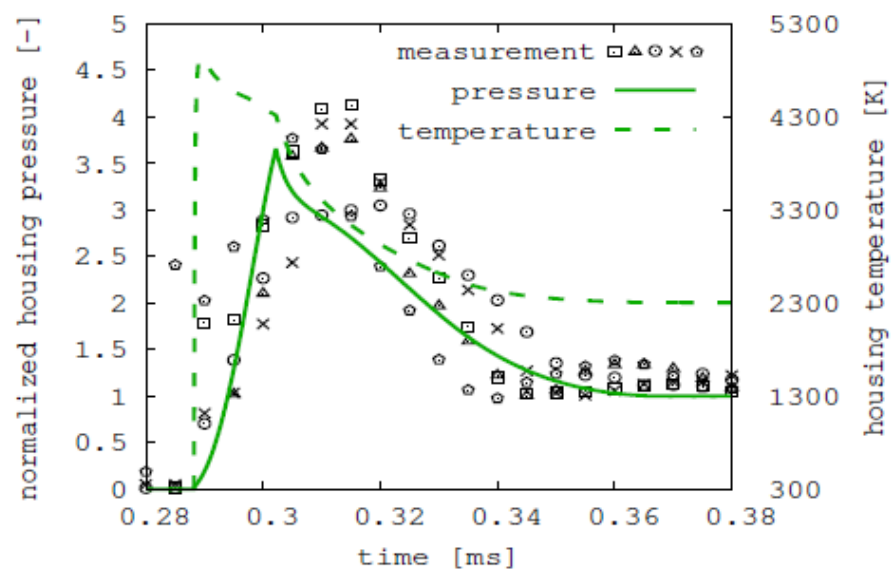

Figure 19 Validation of physical properties during initiator deployment in housing region. Each symbol represents one single recorded dataset normalized by the pressure level of the inflator filled with the gas.

Interestingly, no negative exponential pattern of pressure evolution of the pure gas released was observed both in the measurement data and modeling results in the case of the pot membrane burst period. This phenomenon indicated a supplement from the initiator after the breaking of the membrane.

Pressure and temperature evolution in the housing region (Figure 19) and the initiator (Figure 20) revealed the dynamics of the ignition chain. Briefly, once the initiator cap is broken, the mass and energy flow from the initiator rapidly increase the pressure in the housing region until the membrane attains the limiting stress. On the other hand, since the void in the housing is much smaller comparing to the $40 \mathrm{ccm}$ vessels, the temperature rapidly reaches its peak value and is gradually affected by the energy supply against the heat loss impact afterward. A slight hump after $0.3 \mathrm{~ms}$ could be seen in Figure 20, referring to the end of initiator contribution in the housing region. Following this, the temperature drops very fast until the membrane bursts, where the mass and energy budget of conservation in the housing region are in deficit. The pressure and temperature drop accordingly. 


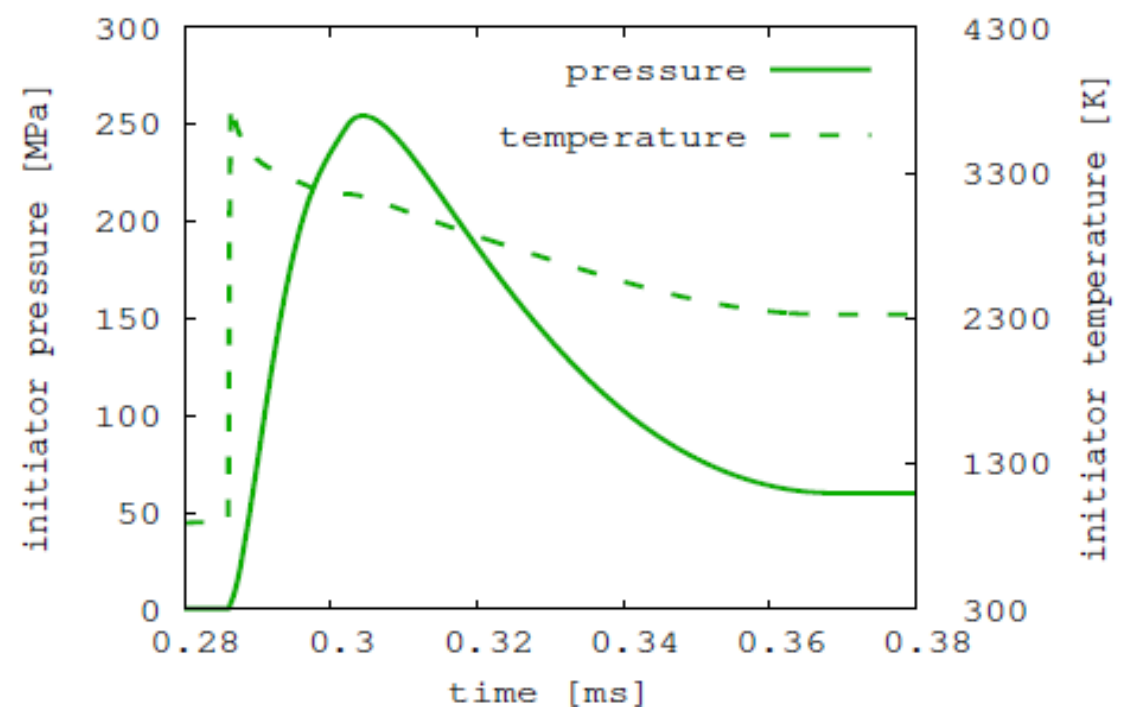

Figure 20 Evolution of physical properties in the initiator during deployment in inflator housing.

The evolution of the physical properties in the initiator presented in Figure 20 was very similar to one shown in Figure 17, indicating that the main function of the selected initiator was not largely affected by the inflator design. The difference in the pressure evolution was mainly due to the different pressure conditions in the passive domain (e.g., vessel and housing), determining the transitional mass and energy flow rates.

\subsection{CFD Simulation in Inflator Integrity Modeling}

The propagating shock is the main characteristic to trigger the inflation of cold gas relevant inflators, whose features depend on the wave transmission medium, the geometry of the gas container, and the physical properties created by the initiator. The representation of physical properties in the inflator due to initiator ballistics was captured in the CFD simulations, which calculated the mass, momentum, and energy transport in a highly transient 3D compressible flow manner.

\subsubsection{Determination of Calculation Domain and Numerical Setup}

A simplified inflator was configured as the calculation domain for CFD simulations (Figure 21). It was comprised of tube-shaped gas storage space that served as the main arena for wave propagation. The housing geometry and the baffle on the outlet membrane region were built to achieve realistic wave intensity and flow conditions. The entire domain structurally meshed with the local refinement on the baffle region in a 3D representation had around $600 \mathrm{~K}$ degrees of freedom. 


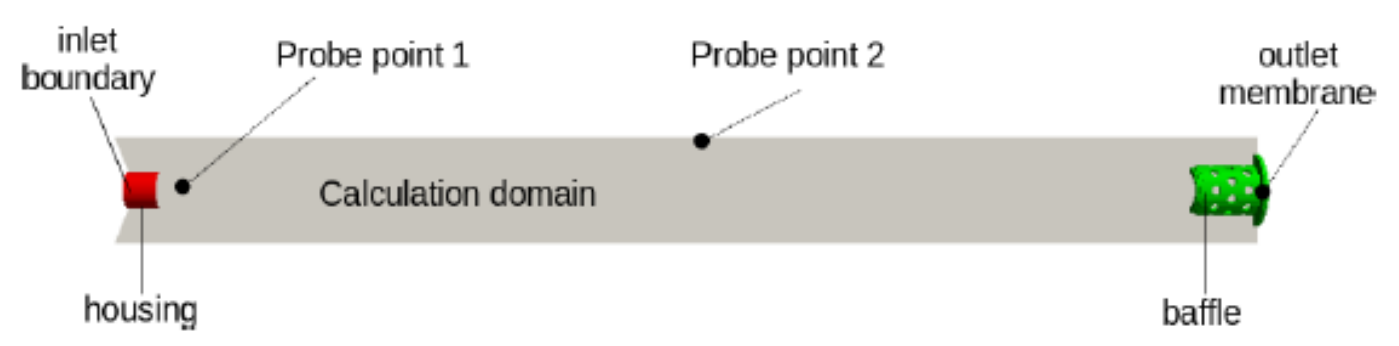

Figure 21 Sketch of CFD simulation domain.

Assuming that the gas stored in the inflator had no reverse effect on the initiator burning condition, the coupling of initiator characteristics with the inflator simulation was determined by the boundary conditions applied in the housing region. Thereby, the pressure and the temperature evolution calculated in the previous section were implemented as Dirichlet type of transient boundary conditions for the simulation (Figure 19). Non-slip conditions were set elsewhere for the rest of the domain boundaries, and the gas container remained sealed during the entire process. The membrane region was also defined as a wall since the main objective of the simulation was to capture the wave propagation. Initial conditions were defined according to the realistic inflator integrity with pressure and molar weight of the stored gas mixture and the preconditioned temperature.

Simulations were carried out using open source CFD software OpenFOAM ${ }^{\circledR}$ 3.1.1. The sonicFoam based transient solver that applies the momentum and energy equations incorporated with PISO algorithms was used to solve the pressure condition in a single species compressible flow regime. The ideal gas law was applied for the equation of state coupling the density to the continuity equation, and the standard $k-\varepsilon$ model was employed to model the relevant turbulence impacts in the flow field.

Euler implicit method and the 2nd order central differencing scheme were used for the calculation. The constant time step was set with the maximal Courant number controlled under 0.3 during the entire calculation. A grid sensitivity study was conducted, and the simulations were run on three additional meshes. The results showed sharper resolution capturing the wavefront in fine mesh, but no difference in the wave intensity was observed.

Three probe points along the tube were selected to realize the temporal evolution of the physical properties during the wave propagation. These included (1) right after the housing region (Probe 1), (2) on the tube inner wall in the middle of the shock tube (Probe 2), and (3) outlet membrane position (Probe 3), as shown in Figure 21. Simulations were carried out until the strongest wavefront reached the outlet disc, suggesting the opening of the stored gas system, thus, the beginning of the inflation.

\subsubsection{Simulation Results and Model Validation}

The first impression of the simulation results indicated transient characteristics. Figure 22 shows the pressure distribution in the shock tube at different moments. The generation of shock and its development into an arc shape wavefront was strongly visible. During the temporal evolution, wavefront propagated from the housing side toward the outlet disc and lasted for $0.35 \mathrm{~ms}$ until the front attained the outlet disc. The intensity was reduced due to the viscous effects of the transmission medium. The wavefront encountered the baffle closed to the outlet membrane region, 
serving as an obstacle. Consequently, the refracts and overlaps of the wavefront caused a higher pressure magnitude on the outlet membrane than on the inner wall of the tube (Figure 23).

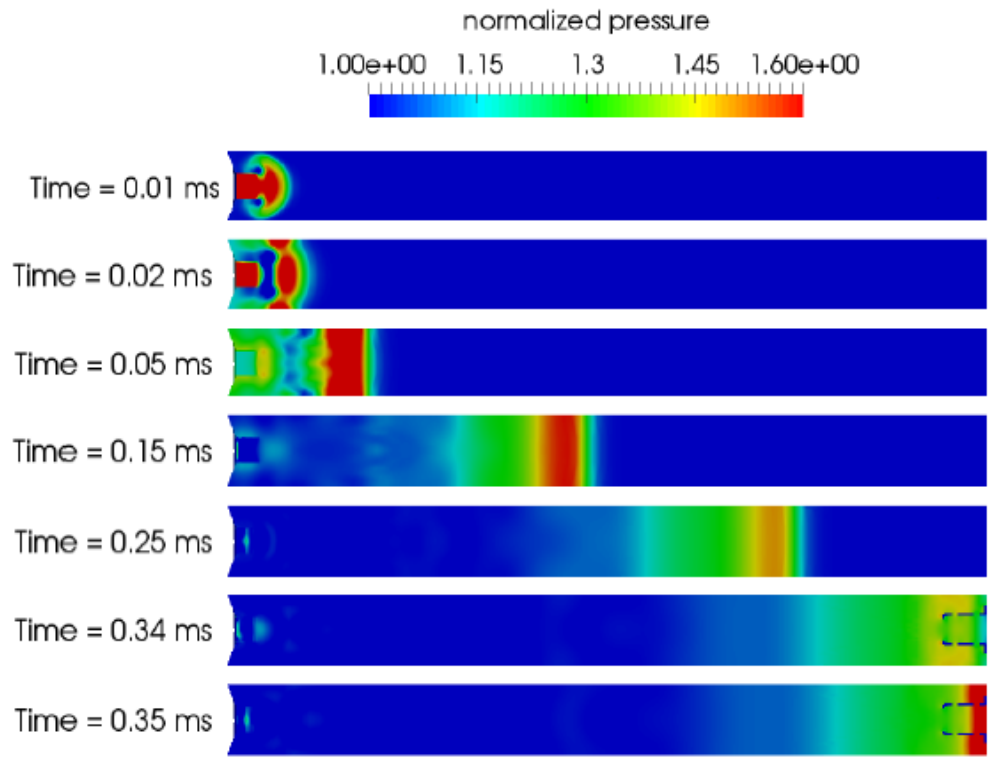

Figure 22 Shock wave propagation and pressure distribution in the inflator tube. Values are normalized by the initial pressure level of the filled gases.

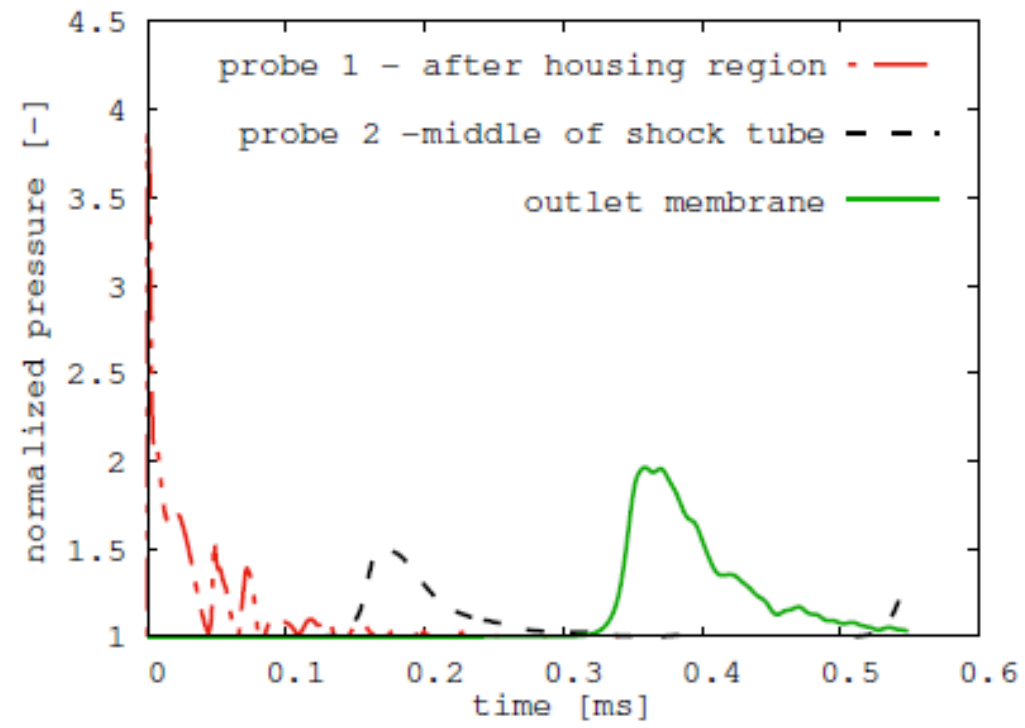

Figure 23 Pressure evolution at the selected monitoring points (Figure 21). Values are normalized by the initial pressure level of the filled gas in the inflator.

Due to the high dynamics and intensity of wave properties, in particular, the accompanying noise of the measured signals, it was challenging and difficult to get the measurements of the shock propagation and to extract the viable data. Figure 24 compares the numerical results with measured peak pressure values, which could be interpreted as the highest shock level on the outlet membrane position. However, a quantitative comparison was not feasible due to the incapability of the measured data to deliver a clear image of the real situations. On the other hand, the potential bias 
between the modeling results and reality could always be traced back to the deviations in the initiator ballistics, the material behavior of the inlet membrane regarding burst patterns, and the filled gas weight and the species mixing ratio. Nevertheless, a rational pressure evolution with its peak value in the middle range of the provided measurement data was shown, and the corresponding modeling methodology and simulation strategy could be validated.

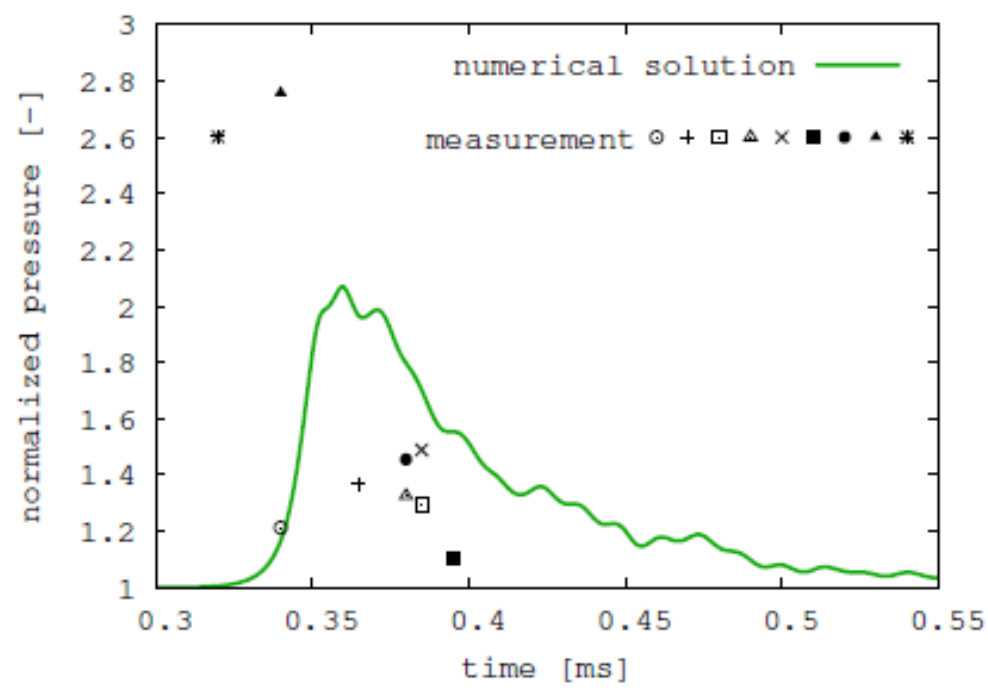

Figure 24 Validation of pressure evolution on the outlet membrane. Each symbol represents the peak value of one single recorded dataset. Values are normalized by the initial pressure level of the filled gas in the inflator.

\subsection{Sensitivity Study of Ignition Chain Components}

A better understanding of inflator function could be striven by the parametric study of the steering design components. In this section, the impact of various elements of the ignition chain, such as the equivalent maximum stress of the inlet membrane, the free volume in the housing region, and the initiator ballistics, on inflator integrity was investigated.

\subsubsection{Impact of Maximum Inlet Membrane Strain}

The inlet membrane serves as an isolator between the housing and the stored gas. The opening of the membrane immediately produces a discontinuous interface between the two regions, acting as a shock propagating toward the outlet membrane. The higher the applied membrane strain, the higher will be the pressure difference between the regions. Besides, the higher discontinuity leads to a stronger shock, making the initiator ballistics exceed the bordering pressure level.

Summarizing the measurement data, three standard deviations over the averaged measured values were selected in correspondence with the six-sigma principle to test the limit of the system. Also, the resulting pressure and temperature in the housing region served as the boundary conditions for the CFD simulations (Figure 25a). 


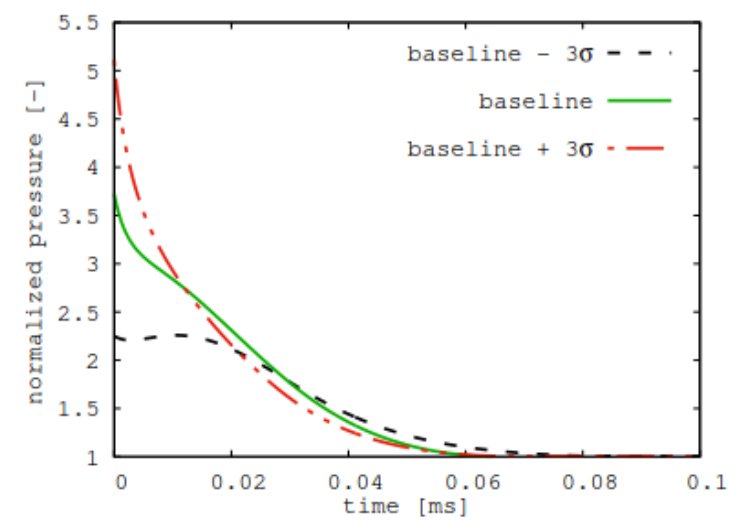

(a)

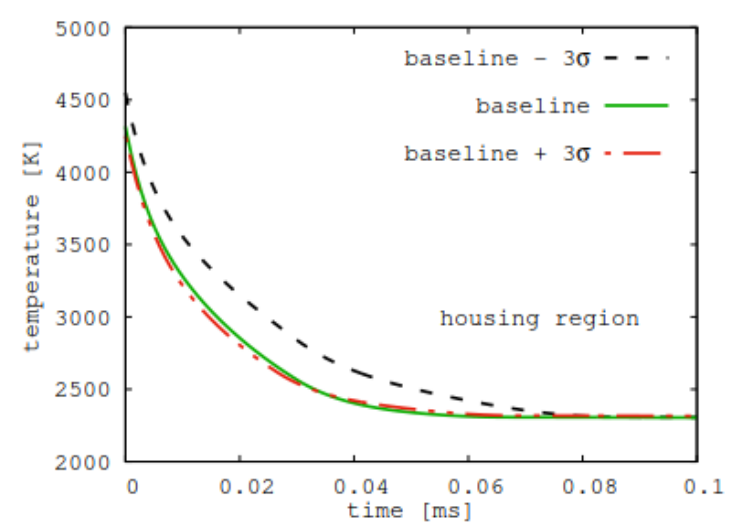

(b)

Figure 25 Parameter study of the inlet membrane burst pressure level in the initiator generated inflow conditions. (a) Pressure and (b) temperature conditions in the housing. Values are normalized by the initial pressure level of the filled gas in the inflator.

Figure 26 shows the pressure evolution along the shock tube. Surprisingly, the high-pressure difference on the bursting moment did not always lead to high shock wave intensity. Instead, the intensity of the pressure wave dropped rapidly once the propagation started. On the resulting outlet membrane position, the pressure magnitude of all three variations was barely identical.

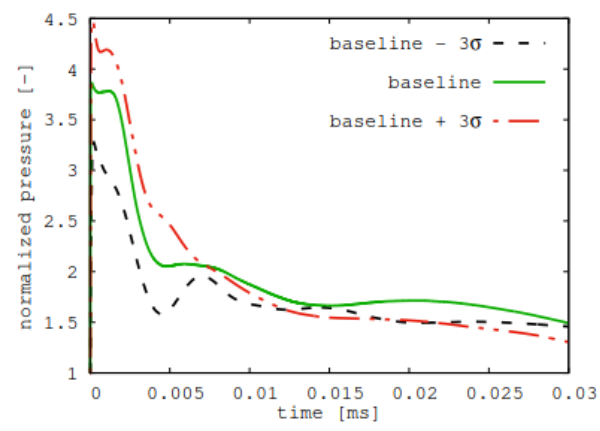

(a)

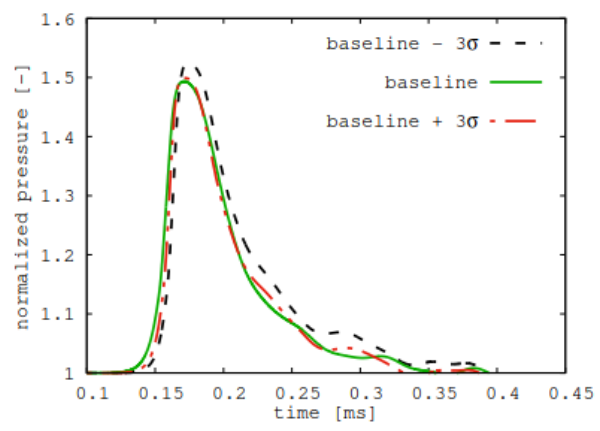

(b)

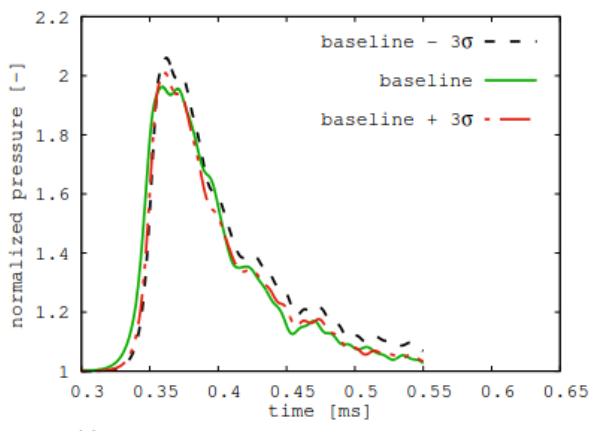

(c)

Figure 26 CFD results of the inlet membrane burst pressure parameter study. Values are normalized by the initial pressure level of the gas in the inflator. (a) Wave intensity (a) right after housing region (Probe 1 ) and (b) in the middle of shock tube (Probe 2), and (c) at outlet membrane. 


\subsubsection{Impact of Housing Volume}

The impact of housing volume was evaluated by the same strategy mentioned above. The results of the house modeling shown in Figure 27 were obtained by doubling the free space in the housing region and reducing it by half. A hump was observed in the pressure evolution of the one with less housing space (Figure 27a). This was attributed to the early opening of the system before the completion of the initiator contribution, i.e., the burning of the pyrotechnic in the initiator kept on going even after the opening of the system. Thus, it could be said that lesser space or weaker membrane bursting stress results in a more remarkable hump. The CFD simulation results of the pressure profiles with hump resulted in more intensive propagation, even though their temperature levels were comparatively lower (Figure 28). A rough insight into the correlation between boundary profiles and shock propagation focuses rather on the pressure level, in particular, the evolution after the housing system is opened.

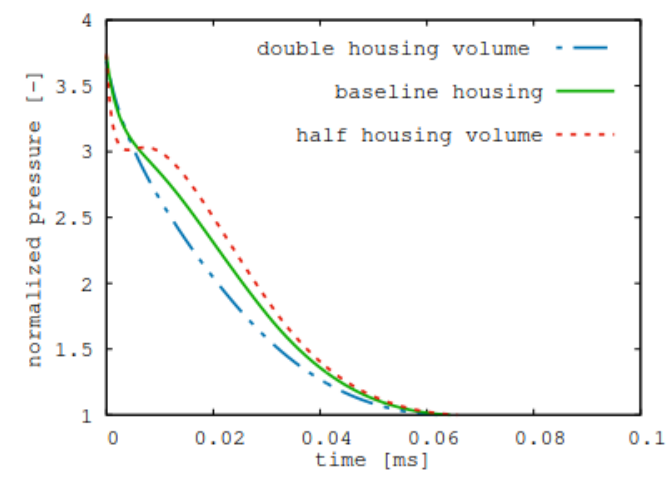

(a)

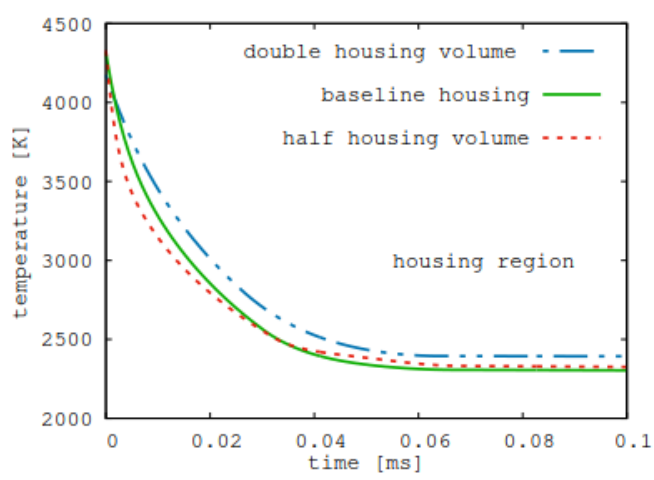

(b)

Figure 27 Parameter study of housing volume: initiator generated inflow conditions. (a) Pressure and (b) temperature conditions in the housing. Values are normalized by the initial filled gas pressure level in the inflator. 


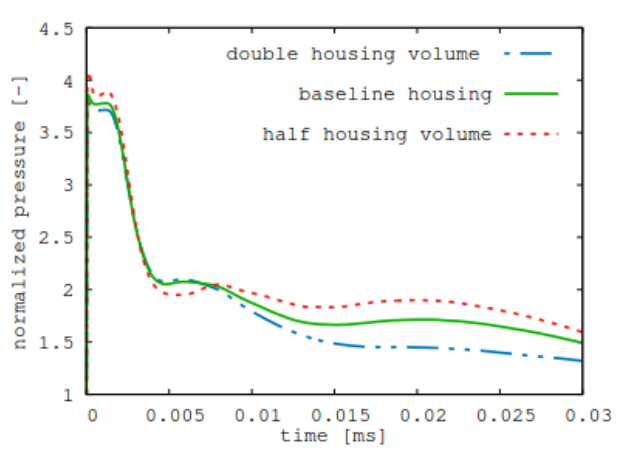

(a)

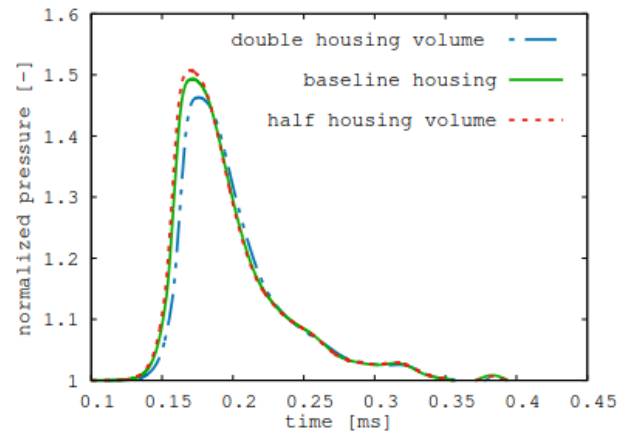

(b)

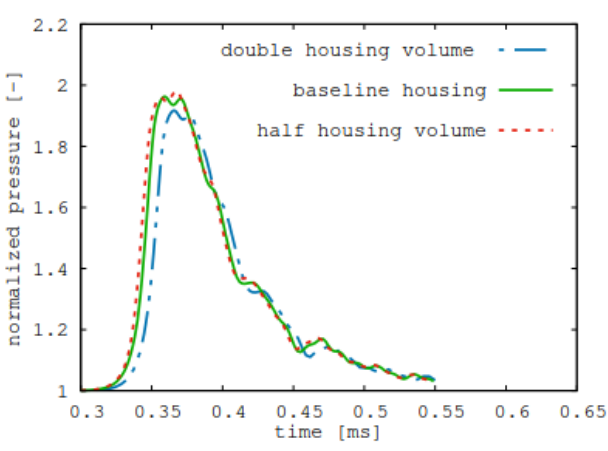

(c)

Figure 28 CFD results of housing volume parameter study. Values are normalized by the initial filled gas pressure level in the inflator. Wave intensity (a) right after housing region (Probe 1), (b) in the middle of shock tube (Probe 2), and (c) at the outlet membrane.

The results of the inlet membrane and housing volume study gave new insights into the inflator functionality, where the quality of the propagating shock did not simply depend on the initial discontinuity but also the evolution of the physical properties in the housing region after the discontinuity. On emphasizing the replenishment in the housing region after the burst of the inlet membrane, initiator ballistic characteristics tend to be the key factor in the inflator functionality. The ignition chain components such as the inlet membrane and housing play only a supportive role in preserving the wave intensity.

\subsection{Impact of Initiator Characteristics on the Inflator Integrity}

To demonstrate the initiator ballistics as the most influencing factor in the cold gas inflator functionality, the shock propagation at the inflator level was evaluated based on the propellant load and the loading behavior between the charges.

\subsubsection{The Varying Amount of THPP}

Following the same initiator configuration as described at the beginning of this section, the THPP amount was varied by increasing and reducing the nominal THPP load by $15 \%$ and $30 \%$, respectively. The corresponding performance in a $40 \mathrm{ccm}$ vessel shown in Figure 29 indicated a direct correlation between the peak pressure level and the propellant amount. A significantly higher temperature level did not depend on the highly loaded propellant, while the temperature evolution in the vessel 
(Figure 29b) correlated to the thermal-chemical properties as already described. The difference in pressure level in the vessel indicated the amount of gas produced during the combustion.

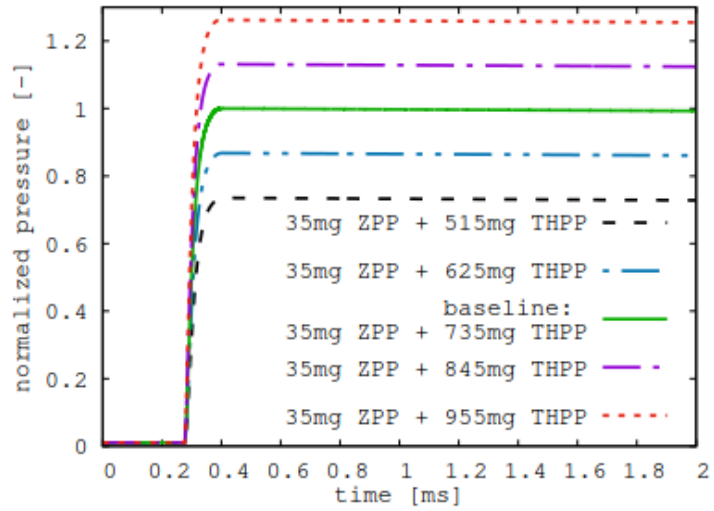

(a)

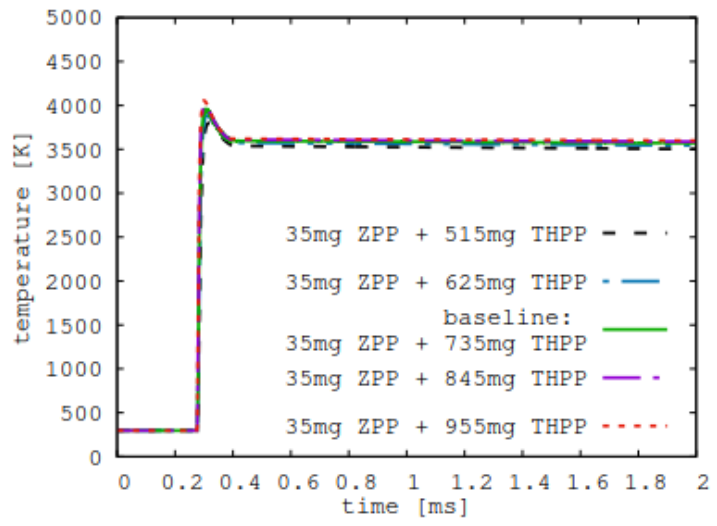

(b)

Figure 29 The impact of THPP amount on the (a) pressure and (b) temperature evolution during a closed bomb test in a $40 \mathrm{ccm}$ vessel. Values are normalized by the peak pressure value of baseline configuration measurement at room temperature (Figure 16).

Following the same modeling strategy, the initiator deployment in the housing region, the coupling to CFD simulations, the pressure and temperature boundary conditions, and the shock intensity on the outlet membrane demonstrated a similar correlation. i.e., the higher the initiator load, the stronger the shock expected in the inflator level (Figure 30). Besides, the stronger shock propagated faster. As a result, the wavefront arrived earlier at the outlet membrane (Figure 31).

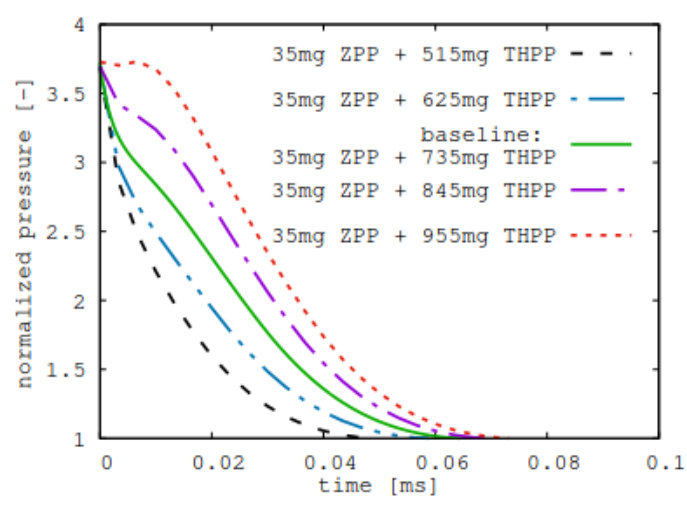

(a)

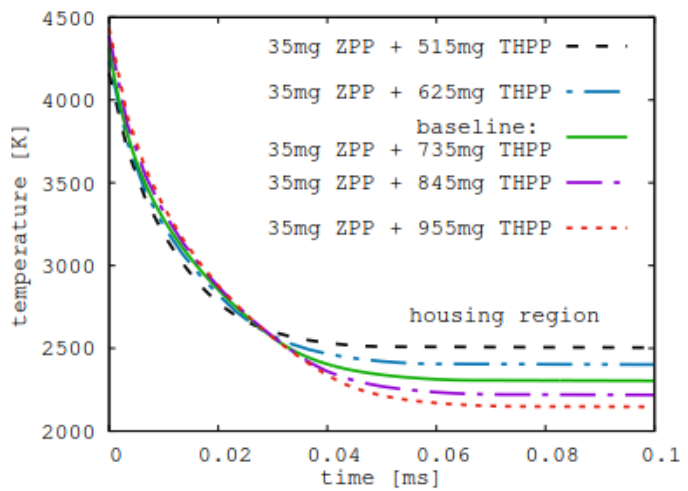

(b)

Figure 30 Parameter study of THPP amount: initiator generated inflow conditions. (a) Pressure and (b) temperature conditions in housing. Values are normalized by the initial pressure level of the filled gas in the inflator. 


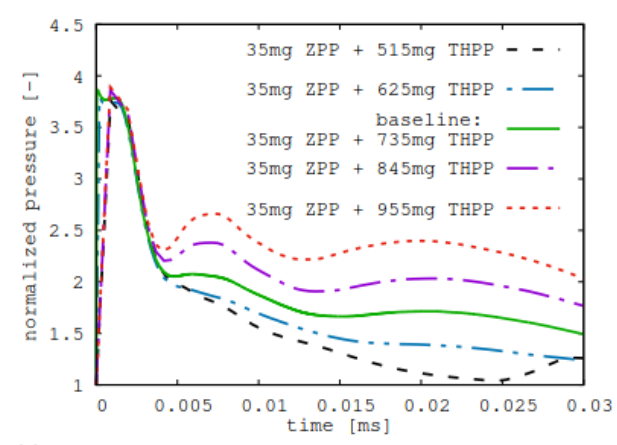

(a)

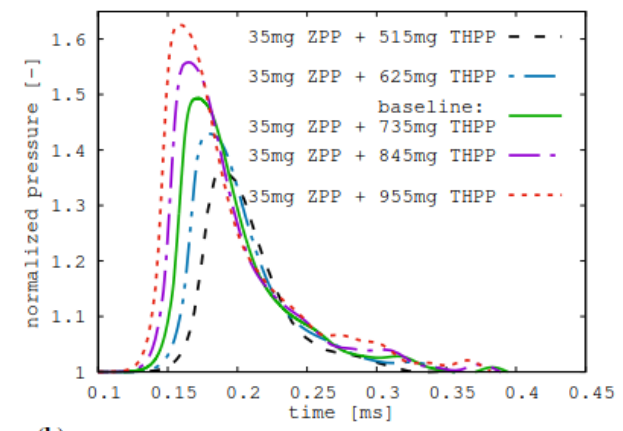

(b)

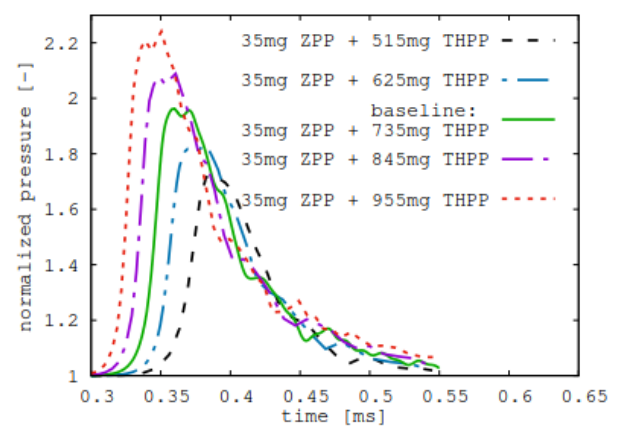

(c)

Figure 31 CFD results of THPP-amount parameter study. Values are normalized by the initial filled gas pressure level in the inflator. Wave intensity (a) right after housing region (Probe 1), (b) in the middle of shock tube (Probe 2), and (c) at the outlet membrane.

\subsubsection{Variation in the Mass Behavior of ZPP/THPP}

Another way of investigating the shock intensity is to vary the weight in each charge by fixing the total propellant load in the initiator. The pressure evolution in the housing corresponding to the shifting of weight from THPP to ZPP is shown in Figure 32a. The results also showed that the temperature level in the initiator increased with the increasing amount of ZPP (Figure 32b) due to the higher combustion temperature of ZPP than THPP. Thus, not only differences in pressure level, species, and temperature are also relevant to the amount of gas produced.

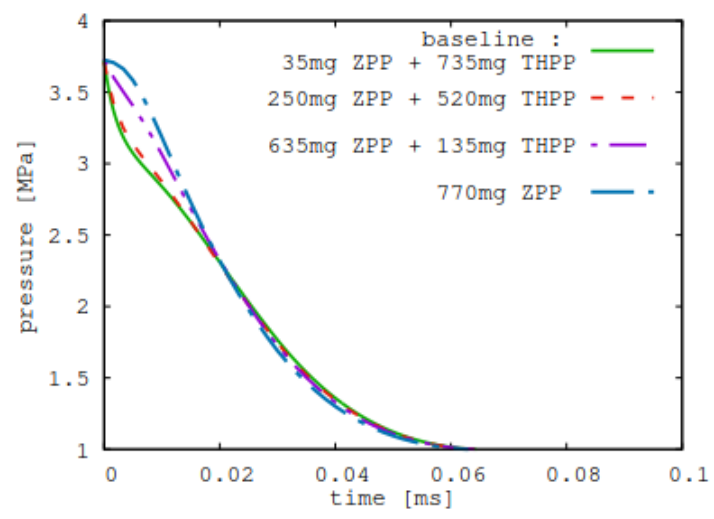

(a)

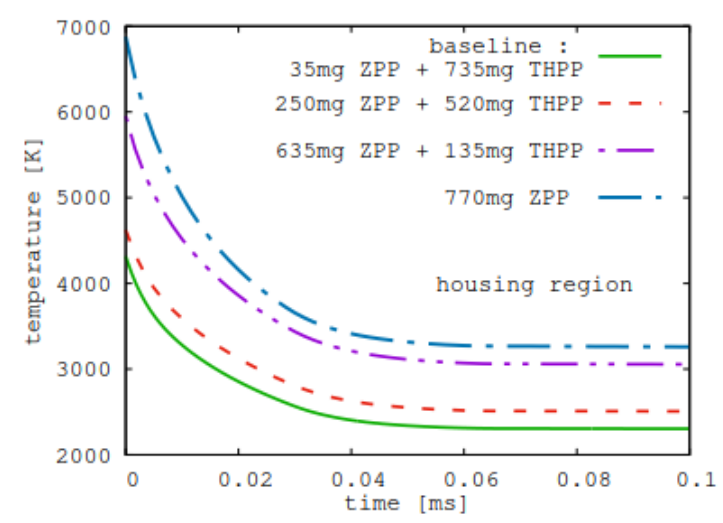

(b)

Figure 32 Parametric study of ZPP-THPP weight proportion: initiator generated inflow conditions. (a) Pressure and (b) temperature conditions in housing, values are normalized by the initial filled gas pressure level in the inflator. 
The physical properties in the housing region and the respective CFD results of shock propagation are shown in Figures 32 and 33. In the housing region, initiators with the larger portion of ZPP resulted in higher temperature evolution due to their intrinsic differences in combustion temperature, whereas only a slight distinction could be seen for the pressure evolution. However, different characteristics were observed in the shock tube simulation (Figure 31). The hump in the pressure evolution closed to the inlet boundary (Figure 31a) became stronger with the increasing proportion of ZPP. This behavior lasted until the shock arrived at the outlet membrane along with the higher pressure level.
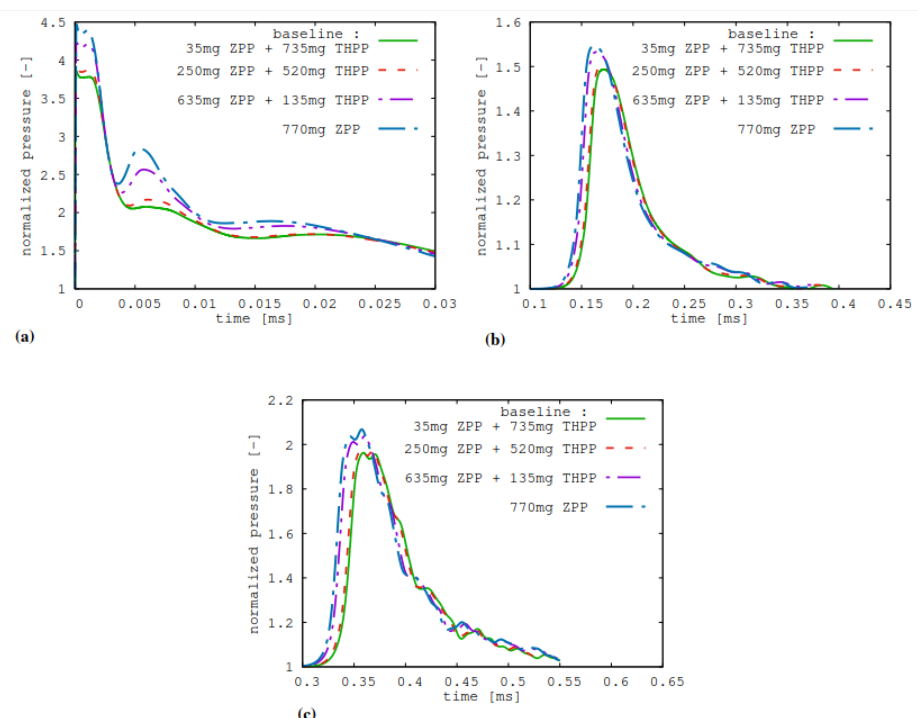

Figure 33 CFD results of ZPP-THPP weight behavior parameter study. Values are normalized by the initial filled gas pressure level in the inflator. Wave intensity (a) right after housing region (Probe 1), (b) in middle of shock tube (Probe 2), and (c) at outlet membrane.

The closed bomb pressure evolution showed no explicit correlation with the resulting wave intensity in the shock tube. Moreover, the initiator with the highest pressure peak in the vessel did not correlate to the production of the highest shock, as observed in Figures 34a and 33c.

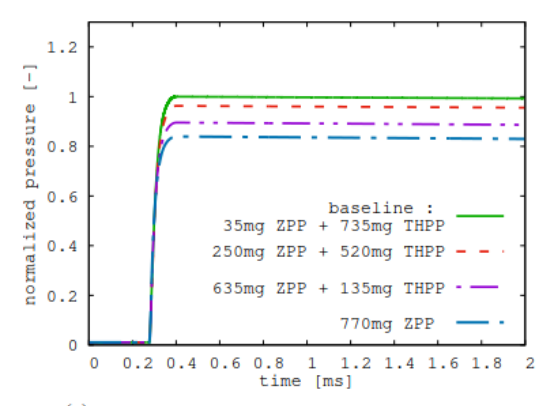

(a)

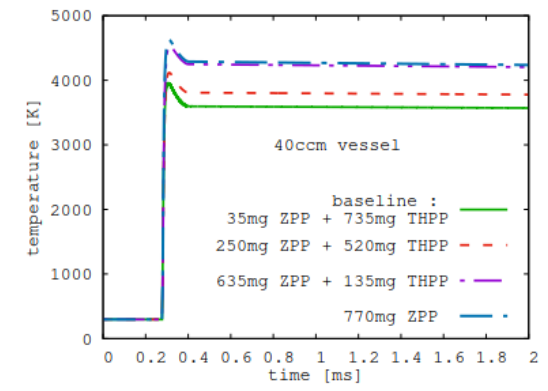

(b)

Figure 34 Parameter study of ZPP-THPP weight portion: results of closed bomb test in a $40 \mathrm{ccm}$ vessel. (a) Pressure and (b) temperature evolution. Values are normalized by the peak value of the measurement in baseline configuration at room temperature (Figure 16). 
These results further explained the shock dynamics. At first, the shock was generated due to discontinuous pressure distribution, and the wave intensity faded along with the propagation. The correlation of temperature and pressure boundary impact revealed that the remaining or replenished energy level in the boundary system (housing) was the key index to maintain the stronger wave propagation.

Concerning the product development, the summary of simulation results led to a design dilemma in the inflator framework, since no correlation existed between the shock intensity and the closed bomb test pressure peak. On the contrary, the parametric study showed a trend toward greater intense shock with the initiator propellant amount, which was the most sensitive parameter in the inflator ignition chain.

Combining the information gained in the early sections of this article, the design parameters of an inflator system could be optimized in the framework of modeling and simulation incorporated with the limited amount of measurement data. Competent simulation results presented all related physical properties, which could even reduce the risk due to the missing information ascribed to the difficult measurement process, and improved the product functional safety.

\section{Summary and Conclusion}

In the present work, an analytical model describing the interior ballistics of a pyrotechnic initiator was proposed. By applying the propellant thermal-chemical features incorporated with passive systems (e.g., vessel and housing), the temperature, pressure, and physical characteristics such as mass and energy transition over systems during initiator deployment could be evaluated.

The characteristic feature of this work included its extension from the underlying methodology to the description of realistic configurations based on the impact of initiator bridge wire, metal cap, and the dynamics of the distributed grain size. These modeling strategies demonstrated their validity in the framework of burn rate parameters evaluation and the validation of ZPP-ZPP/THPP initiators. Thereby, harmonizing the thermal-chemical properties calculated by the PEP with the burn rate parameters. The predicted pressure evolutions in the closed bomb test showed quantitative agreement with the measurement data.

The modeling results of an engineering product do not reveal complete physical details behind the complexity since numerous assumptions are made during the modeling procedure to validate the model. For instance, the thermal-chemical interaction of the pyrotechnic was simplified to constant values and the equilibrium thermal state, and the phase change during the deployment was completely neglected. On the other hand, the mechanical breakage of the initiator cap was linked to the material properties, and the heat loss in the system were closely related to the gas flow patterns. All these simplifications in the model, which restrict detailed physics, were rather of great interest for further investigations.

Nevertheless, a chain-wise numerical model following the multi-body-simulation-like principles delivers a rough picture of initiator ballistics with the help of an engineering tool. The application of such models enables the engineers to adapt the product design according to the targeting performance and troubleshoot the root cause or failure mode by fitting the parameters with limited prototyping and testing. Accordingly, an economical product development framework could be realized. 
Extending the vision into the automotive safety system devices, the assessment of inflator functionality concerning the initiator ballistics was the other objective of this work. Given this, a cold gas inflator was selected mainly due to its simple designed functions and the direct correlation between the initiator ballistics and inflator integrity. The proposed model was intended to describe the ZPP-THPP initiator in a $40 \mathrm{ccm}$ vessel, the mechanism of the ignition chain system, and the shock propagation by coupling the physical characteristics in the housing region with the CFD simulations.

Simulation results from the sensitivity study revealed many interesting features. For instance, the pressure condition in the housing region dominated the shock intensity; thus, designating the transient pressure state as boundary conditions for the CFD simulations, referring to the sustainability of the produced mass and energy due to initiator deployment. At the same time, the impact of temperature boundary was rather imperceptible. Moreover, the ignition chain elements such as inlet membrane bursting pressure and housing volume mainly had supporting roles. Small scale variations in these parameters were not expected to have a high impact on the inflator integrity and also the intrinsic restriction of cold gas inflator for large scale parameter variations due to filled gas pressure and mechanical strain of inflator parts.

The coupling of the initiator ballistic model with CFD simulation for shock propagation makes it possible to assess each functional element in detail. With the assistance of high efficient computational technology, the effects of the product tolerance and the potential failure patterns can be predicted and further controlled. Yet, automatized design optimization in ballistics can be established based on such model chains to achieve more efficient configuration for product function and costs

Expanding the spectrum of inflator variance, the insights gained from the cold gas inflator were also valid for double system hybrid inflators with the requirement of stable and strong shock propagation. For such configurations, an initiator no longer creates sustainable pressure in the housing but ignites the propellant pellets in the primary system (housing region). Consequently, the propellant pellets generate high and sustainable pressure levels. However, the implementation of these propellant tablets can lead to other challenges such as ignition quality and tablet breakage, which are related to the mechanical feature. The analysis of the initiator's impacts on the pyrotechnic tablets is a major issue during the initiator application and the development of the pyrotechnic inflator and needs to be further investigated in the future.

\section{Acknowledgments}

We gratefully thank JSS inflator center for the cooperation on this principle investigation as well as providing the measurement data for the model calibration. In particular, the technical support of Dr. Katja Mader-Arndt and JSS Ignition team are very appreciated. The intensive discussion of CFD simulations with Yongxiang Li, M.Sc. of Institute for Energy and Power Plant Technology, Technical University Darmstadt is also greatly acknowledged.

\section{Author Contributions}

P.L. carried out the implementation and analysis. C.Y.C. conducted and coordinated the investigation. A.S. supervised the scientific process. All authors discussed the results and contributed to the final manuscript. 


\section{Competing Interests}

The authors have declared that no competing interests exist.

\section{References}

1. Berger B. Military pyrotechnics. CHIMIA Int J Chem. 2004; 58: 363-368.

2. Montonna RE. Manual of explosives, military pyrotechnics and chemical warfare agents. By Jules Bebie. J Phys Chem. 1943; 47: 465-466.

3. Lucy M, Hardy R, Kist E, Watson J, Wise S. Report on alternative devices to pyrotechnics on spacecraft. Hampton, VA: National Aeronautics and Space Administration, Langley Research Center; 1996; NASA-TM-110470.

4. Fureby C, Tabor G, Weller HG, Gosman AD. A comparative study of subgrid scale models in homogeneous isotropic turbulence. Phys Fluids. 1997; 9: 1416-1429.

5. Davenas A. Solid Rocket Propulsion Technology. Oxford: Pergamon Press; 2012.

6. Brauer KO. Handbook of Pyrotechnics. New York: Chemical Publishing Company; 1974. pp.119128.

7. Babrauskas V. Ignition handbook-principles and applications to fire safety engineering, fire investigation, risk management and forensic science. New York: Fire Science and Technology; 2020.

8. Forman D. Automotive initiator technology. Proceedings of the 35th Joint Propulsion Conference and Exhibit; 1999 June 20th-24th; Los Angeles, CA, US. Reston: American Institute of Aeronautics and Astronautics. pp.2422.

9. Jang SG, Lee HN, Oh JY. Performance modeling of a pyrotechnically actuated pin puller. Int J Aeronaut Space Sci. 2014; 15: 102-111.

10. Gonthier KA, Powers JM. Formulations, predictions, and sensitivity analysis of a pyrotechnically actuated pin puller model. J Propuls Power. 1994; 10: 501-507.

11. Gonthier K, Kane T, Powers J. Modeling pyrotechnic shock in a nasa initiator driven pin puller. Proceedings of the 30th Joint Propulsion Conference and Exhibit; 1994 June 27th-29th; Indianapolis, IN, US. Reston: American Institute of Aeronautics and Astronautics. pp.3054.

12. Braud AM, Gonthier KA, Decroix ME. System modeling of explosively actuated valves. J Propuls Power. 2007; 23: 1080-1095.

13. Rossi C, Esteve D, Mingues C. Pyrotechnic actuator: A new generation of Si integrated actuator. Sens Actuator A Phys. 1999; 74: 211-215.

14. Chang KY. Pyrotechnic devices, shock levels and their applications. Proceedings of the Pyroshock Seminar, ICSV9; 2002 July 8th-11th; Orlando, FL, US. Pasadena: Jet Propulsion Laboratory.

15. Bement LJ, Schimmel ML. A manual for pyrotechnic design, development and qualification. Hampton: National Aeronautics and Space Administration, Langley Research Center; 1995.

16. Seo YD, Kim GW, Hong BS, Kim JH, Chung SH, Yoh Jl. Automotive airbag inflator analysis using measured properties of modern propellants. Trans Korean Soc Automot Eng. 2010; 18: 53-62.

17. Butler PB, Krier H, Faigle EM, Semchena JH, Thompson R. Numerical simulation of passengerside automotive airbag inflators. SAE Technical Papers. 1992; 920848.

18. Ballesteros T, Arana JI, de Ezcurdia AP, Alfaro JR. Development and validation of automatically deployable ROPS based on airbag inflator technology. Biosyst Eng. 2015; 130: 92-105.

19. Lian W, Narwani G. Effect of gas thermodynamics on the aggressiveness of airbag inflator. SAE 
Transactions. 1998. pp.2422-2429.

20. Han DH, Sung HG, Ryu BT. Numerical simulation for the combustion of a zirconium/potassium perchlorate explosive inside a closed vessel. Propellants Explos Pyrotech. 2017; 42: 1168-1178.

21. Han DH, Yoo YL, Sung HG. An analysis of the different flow characteristics of a closed bomb test in cylindrical and spherical closed vessels. Int J Aeronaut Space Sci. 2019; 20: 150-156.

22. Shimpi SA, Krier $\mathrm{H}$. The closed bomb test for the assessment of solid propellant grains utilized in guns. Combust Flame. 1975; 25: 229-240.

23. Cha SW, Woo J, Kim YC, Oh SH, Cho JY, Kim JH, et al. Combustion modeling of explosive for pyrotechnic initiator. J Korean Soc Propuls Eng. 2017; 21: 39-48.

24. Kuo Jh, Goldstein S. Dynamic analysis of nasa standard initiator driven pin puller. Proceedings of the 29th Joint Propulsion Conference and Exhibit; 1993 June 28th-30th; Monterey, CA, US. Reston: American Institute of Aeronautics and Astronautics. pp.2066.

25. Powerst JM, Gonthier KA. Sensitivity analysis for a pyrotechnically actuated pin puller model. Stroke. 1994; 9: 16.

26. Gonthier KA, Powers JM. Choked flow effects in the NSI driven pin puller. Proceedings of the Second NASA Aerospace Pyrotechnic Systems Workshop; 1994 February 8th-9th; Albuquerque, NM, US. Cleveland: NASA Lewis Research.

27. Lee HS. Unsteady gasdynamics effects in pyrotechnic actuators. J Spacecr Rockets. 2004; 41: 877-886.

28. Brown WK, Wohletz KH. Derivation of the Weibull distribution based on physical principles and its connection to the Rosin-Rammler and lognormal distributions. J Appl Phys. 1995; 78: 27582763.

29. Hwang DH, Han DH, Han JH, Sung HG, Ryu BT. Separation behavior of pyrotechnically actuated device considering small-volume effect of combustion chamber. J Spacecr Rockets. 2020; 57: 823-834.

30. Hsieh WH, Sun LY, Chen JK, Wang SW. Theoretical simulation of combustion processes of airbag inflators. P I Mech Eng D J Aut. 2001; 215: 1-9.

31. Merci B, Roekaerts D, Sadiki A. Experiments and numerical simulations of diluted spray turbulent combustion. Dordrecht: Springer; 2011.

32. Crowe CT, Schwarzkopf JD, Sommerfeld M, Tsuji Y. Multiphase flows with droplets and particles. Boca Raton: CRC Press; 2011.

33. Rinne H. The Weibull Distribution: A Handbook. Boca Raton: CRC press; 2008.

34. Russell MS. The chemistry of fireworks. London: Royal Society of Chemistry; 2009.

35. Summerfield M. Burning mechanism of ammonium perchlorate propellants. In: Solid Propellant Rocket Research. Cambridge: Academic Press; 1960. pp.141-182.

36. Shekhar $\mathrm{H}$. Mathematical formulation and validation of muraour's linear burning rate law for solid rocket propellants. Cent Eur J Energetic Mater. 2012; 9: 353-364.

37. Rieger D. Numerische modellierung des aufblasvorgangs eines airbags und der thermochemischen prozesse im gasgenerator. München: Universitätsbibliothek der Technischen Universität München; 2006.

38. Holy JA. Burn rates of $\mathrm{TiH}_{2} / \mathrm{KClO}_{4} /$ viton and output testing of NASA SKD26100098-301 pressure cartridges. Washington, DC: National Aeronautics and Space Administration; 1993; NASA CR188357.

39. Gordon S. Computer program for calculation of complex chemical equilibrium compositions, 
rocket performance, incident and reflected shocks, and chapman-jouguet detonations. Washington, DC: Scientific and Technical Information Office, National Aeronautics and Space Administration; 1976; NASA SP-273.

40. SAE. SEA USCAR-28. Initiator technical requirements and validation. Warrendale: SAE International; 2005. doi: 10.4271/USCAR28.

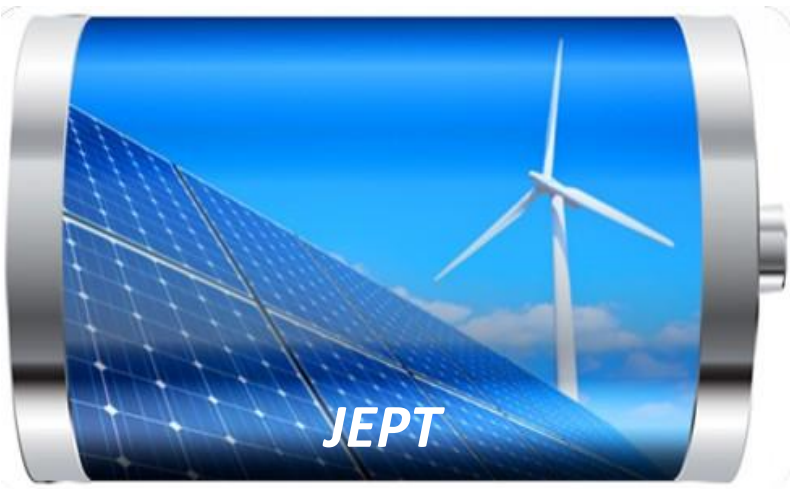

Enjoy JEPT by:

1. Submitting a manuscript

2. Joining in volunteer reviewer bank

3. Joining Editorial Board

4. Guest editing a special issue

For more details, please visit:

http://www.lidsen.com/journal/jept 